\title{
Forecast indices from a ground-based microwave radiometer for operational meteorology
}

\author{
D. Cimini ${ }^{1,2}$, M. Nelson ${ }^{3}$, J. Güldner ${ }^{4}$, and R. Ware ${ }^{3,5}$ \\ ${ }^{1}$ IMAA-CNR, Potenza, Italy \\ ${ }^{2}$ CETEMPS, University of L'Aquila, L'Aquila, Italy \\ ${ }^{3}$ Radiometrics, Boulder, Colorado, USA \\ ${ }^{4}$ DWD, Meteorological Observatory Lindenberg - Richard Aßmann Observatory, Lindenberg, Germany \\ ${ }^{5}$ UCAR, Boulder, Colorado, USA \\ Correspondence to: D. Cimini (cimini@imaa.cnr.it)
}

Received: 20 June 2014 - Published in Atmos. Meas. Tech. Discuss.: 14 July 2014

Revised: 9 December 2014 - Accepted: 11 December 2014 - Published: 14 January 2015

\begin{abstract}
Today, commercial microwave radiometer profilers (MWRPs) are robust and unattended instruments providing real-time, accurate atmospheric observations at $\sim 1 \mathrm{~min}$ temporal resolution under nearly all weather conditions. Common commercial units operate in the $20-60 \mathrm{GHz}$ frequency range and are able to retrieve profiles of temperature, vapour density, and relative humidity. Temperature and humidity profiles retrieved from MWRP data are used here to feed tools developed for processing radiosonde observations to obtain values of forecast indices (FIs) commonly used in operational meteorology. The FIs considered here include $K$ index, total totals, KO index, Showalter index, T1 gust, fog threat, lifted index, $S$ index (STT), Jefferson index, microburst day potential index (MDPI), Thompson index, TQ index, and CAPE (convective available potential energy). Values of FIs computed from radiosonde and MWRPretrieved temperature and humidity profiles are compared in order to quantitatively demonstrate the level of agreement and the value of continuous FI updates. This analysis is repeated for two sites at midlatitude, the first one located at low altitude in central Europe (Lindenberg, Germany) and the second one located at high altitude in North America (Whistler, Canada). It is demonstrated that FIs computed from MWRPs well correlate with those computed from radiosondes, with the additional advantage of nearly continuous updates. The accuracy of MWRP-derived FIs is tested against radiosondes, taken as a reference, showing different performances depending upon index and environmental situation. Overall, FIs computed from MWRP retrievals agree
\end{abstract}

well with radiosonde values, with correlation coefficients usually above 0.8 (with few exceptions). We conclude that MWRP retrievals can be used to produce meaningful FIs, with the advantage (with respect to radiosondes) of nearly continuous updates.

\section{Introduction}

Commercial microwave radiometers profilers (MWRPs) are robust instruments that perform continuous unattended operations and real-time atmospheric observations at $\sim 1 \mathrm{~min}$ temporal resolution under nearly all weather conditions. MWRPs perform measurement of thermal emission from downwelling brightness temperature $\left(T_{\mathrm{b}}\right)$ in the atmosphere. Most common commercial units operate in the $20-60 \mathrm{GHz}$ frequency ( 0.5 to $1.5 \mathrm{~cm}$ wavelength) range, in which atmospheric thermal emission is influenced by atmospheric temperature, humidity, and the presence of hydrometeors. From calibrated MWRP $T_{\mathrm{b}}$, atmospheric thermodynamic profiles can be retrieved using a variety of inversion methods, as multivariate regression, neural networks, and variational approaches (Solheim et al., 1998; Ware et al., 2003; Löhnert et al., 2004; Cimini et al., 2006, 2010) with an accuracy that is compatible with most of meteorology applications, especially in the lower troposphere (Güldner and Spänkuch, 2001; Hewison, 2007; Cimini et al., 2011; Ware et al., 2013). Due to the increasing distribution, networks of MWRPs are 
being established for climate and meteorology applications (Cadeddu et al., 2013; Cimini et al., 2014).

Currently operational radiosonde launches are normally performed twice daily by national and/or regional weather services (NWS) at hundreds of sites worldwide. Relatively few sites perform launches 4 times a day. Radiosondes are usually launched at synoptic hours (00:00 and 12:00, or 00:00, 06:00, 12:00, and 18:00 UTC), and the observed thermodynamic profiles are assimilated into numerical weather prediction (NWP) model analysis. In addition, the same radiosonde observations are processed locally at NWS to compute forecast indices (FIs) developed starting from some 60 years ago (Showalter, 1947; Fawbush and Miller, 1954; Galway, 1956; George, 1960) which are still broadly used for operational meteorology and local short-term forecast (Andersson et al., 1989; Haklander and Van Delden, 2003; Holtslag et al., 2010). Although the FIs based on sounding observations are rather simple, they perform reasonably well, especially once optimized for site-specific conditions, and show forecast skills that often outperform the skill of modern numerical weather predication models (Kuhlman, 2006; Holtslag et al., 2010). However, these FIs are available at NWS radiosonde sites at the time of radiosonde flight, i.e. usually 2 to 4 times a day. More recently, FIs at higher temporal resolution $(\sim 15 \mathrm{~min})$ became available from geostationary satellite retrievals (König, 2002; König and de Coning, 2009; de Coning et al., 2011). Though they are limited to clear-sky conditions, satellite-based FIs offer the advantage of covering large areas (at continental scale). On the other hand, satellite-based FIs suffer from the lack of quality data in the boundary layer due to the low vertical resolution of satellite observations in the lower troposphere.

The US National Research Council (NRC) recently reported that continuous boundary layer temperature, humidity, and wind observations provide a practical and costeffective means to improve local high-impact weather forecasting (NRC, 2008, 2010). In fact, the structure and variability of the lower troposphere is currently not well known because vertical profiles of water vapour, temperature, and winds are not systematically observed with sufficient spatial or temporal resolution. This lack of observations results in the planetary boundary layer being the single most important under-sampled part of the atmosphere. Consequently, shortterm forecast skill may be poor due to a lack of pertinent data, particularly in the lower troposphere, where severe weather originates.

Conversely, traditional FIs developed for radiosondes can be generated from MWRP retrievals continuously and under nearly all weather conditions. Temperature and humidity profiles are available from MWRP data at $\sim 1$ min resolution. Note that most of the information content resides within the planetary boundary layer (Cimini et al., 2011; Löhnert and Maier, 2012) and that useful information is provided even under precipitation (Cimini et al., 2011; Xu et al., 2014). The high-temporal-resolution MWRP retrievals have recently been exploited in support of nowcasting lowlevel windshear at Hong Kong airport (Chan and Lee, 2011), dynamic weather conditions in US (Knupp et al., 2009), and intense convective weather in Hong Kong (Chan and Hon, 2011) and southeastern India (Madhulatha et al., 2013; Venkat Ratnam et al., 2013). A similar approach, though using a ground-based infrared interferometer, is also reported (Feltz and Mecikalski, 2002; Wagner et al., 2008). In addition, MWRPs have been used together with lidar to measure wind and temperature for wind energy applications (Friedrich et al., 2012), revealing the same accuracy as tower measurements, with the advantage of monitoring stability and turbulence.

Thus, the MWRP-retrieved profiles can be used to feed tools for computing FIs developed for radiosondes profiles, providing timely and continuous FI data. These timely FI data are particularly important for thunderstorm forecast in the 0 to $6 \mathrm{~h}$ range, as recently shown for two tropical sites (Chan, 2009; Chan and Hon, 2011; Madhulatha et al., 2013; Venkat Ratnam et al., 2013). In this paper we extend the application to two sites at midlatitude and to a few additional FIs, demonstrating the ability of MWRP retrievals to provide quality FIs similar to radiosonde, as well as the added value of continuous FI data.

This paper is organized as follows: Sect. 2 describes the data set under consideration; Sect. 3 summarizes the methodology used for data intercomparison; Sect. 4 reports the results of the data analysis; and Sect 5 summarizes the results and draws final conclusions, suggesting possibilities for additional advancements and application of MWVR observations.

\section{Data set}

Data collected at two sites are presented in the following. The first site is in Lindenberg (Germany) at the Meteorological Observatory Lindenberg - Richard Aßmann Observatory (MOL-RAO) operated by the German Meteorological Service (Deutscher Wetterdienst, DWD). The second site is Whistler (Canada) at the meteorological station operated by Environment Canada - Meteorological Service of Canada in support of nowcasting and short-term weather forecasting during the Vancouver 2010 Olympic and Paralympic Winter Games (Mailhot et al., 2010).

\subsection{Radiosonde data}

The radiosondes used in this analysis are Global Positioning System (GPS) enabled RS92-SGP systems, manufactured by Vaisala, providing vertical profiles of pressure, temperature, relative humidity, dew point temperature, and wind at $2 \mathrm{~s}$ resolution. These data are then used to calculate the dew point temperature and the geopotential height according to hydrostatic equilibrium. However, depending upon sensor type, ra- 

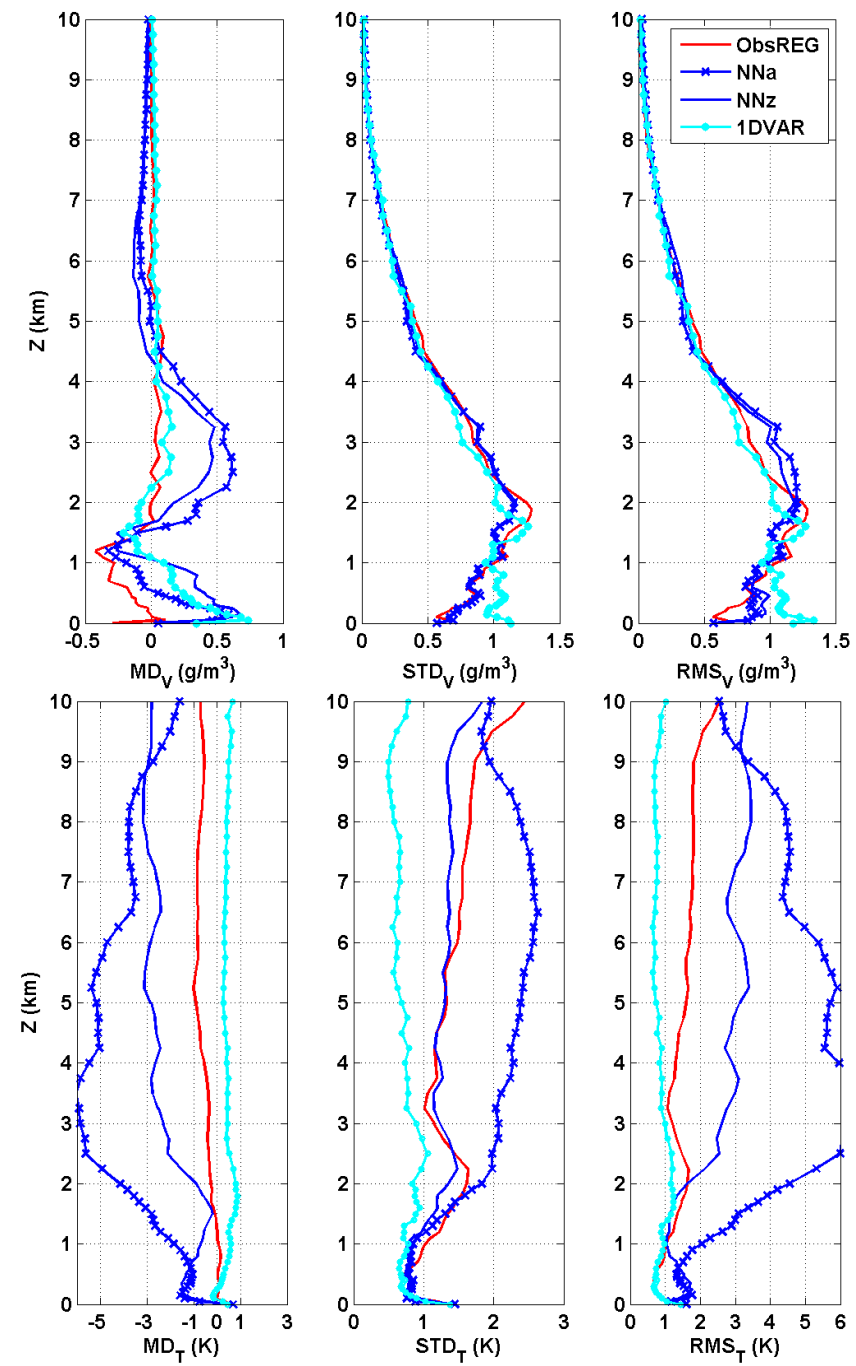

Figure 1. Statistics of water vapour density (top) and temperature (bottom) profiles retrieved with NN, ObsREG, and 1-DVAR, as compared to radiosondes (233 cases). Left: mean difference (radiosonde minus retrievals). Centre: SD difference. Right: rms difference. The legend in the top-right corner indicates the line color/style coding.

diosondes experience some errors, including daytime solar radiation dry bias, horizontal drift, time lag, and calibration errors at low temperatures. Nevertheless, radiosondes remain the de facto standard for upper air monitoring and presently provide the most widely available information on the vertical structure of the troposphere and lower stratosphere. For the type used during the experiment, the specifications for total measurement uncertainty in soundings are $1.0 \mathrm{mb}$ for pressure, $0.5^{\circ} \mathrm{C}$ for temperature, $5 \%$ for relative humidity, and $0.2 \mathrm{~m} \mathrm{~s}^{-1}$ for wind speed (Vaisala, 2013). Four radiosondes per day were launched at standard synoptic hours (00:00, 06:00, 12:00, and 18:00 UTC) from the two sites considered in this study.
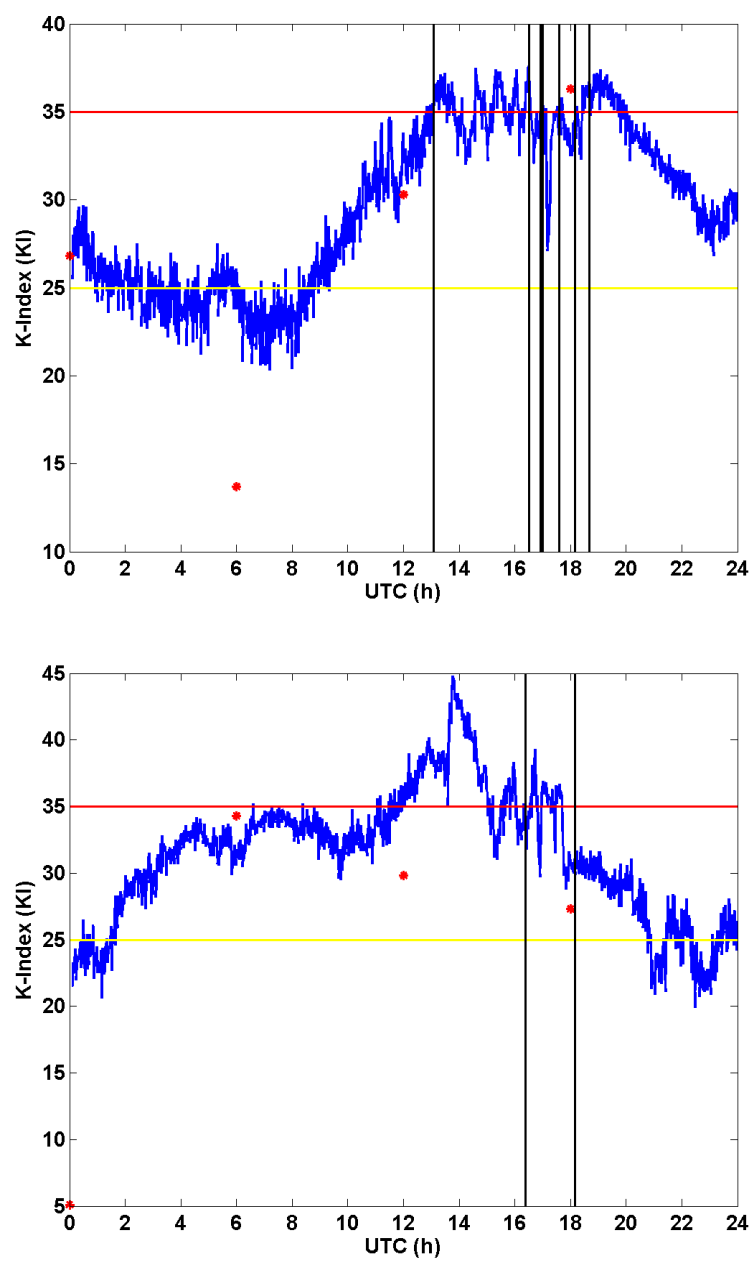

Figure 2. Top: $24 \mathrm{~h}$ time series of $K$ index computed from MWRP $\mathrm{NNz}$ retrievals (blue line), and radiosonde profiles (red dots) for 12 August 2010. Thunder near Lindenberg started at 13:05 and lasted until 18:40 UTC; vertical black lines indicate the time of thunder detection. Yellow and red lines show the boundaries for weak-to-moderate and moderate-to-strong thunderstorm potential thresholds, respectively. Bottom: case of 15 August 2010. Thunder near Lindenberg was reported between 16:10 and 18:05 UTC.

\subsection{MWRP data}

The MWRP data used in this analysis are provided by two MP-3000A units manufactured by Radiometrics. The MP3000A units include a scanning multichannel microwave radiometer; a one-channel broadband infrared (IR) radiometer; and surface pressure, temperature, and humidity sensors. The MWRP IR radiometer (one channel covering approximately 9.6-11.5 $\mu \mathrm{m}$ ) measures sky IR temperature and gives information on cloud-base temperature. The MWRP meteorology sensors measure temperature $\left(T_{\mathrm{s}}\right)$, pressure $\left(P_{\mathrm{s}}\right)$, and relative humidity $\left(\mathrm{RH}_{\mathrm{s}}\right)$ at the instrument level. The multichannel microwave radiometer can observe $T_{\mathrm{b}}$ at up to 35 channels in the $20-60 \mathrm{GHz}$ frequency ( 0.5 to $1.5 \mathrm{~cm}$ wavelength). In this 
Table 1. Summary of MWRP characteristics.

\begin{tabular}{ll}
\hline Channels & 22 \\
\hline Frequencies $(\mathrm{GHz})$ & $22.234,22.5,23.034,23.834,25.0,26.234,28.0,30.0,51.248,51.76,52.28$, \\
& $52.804,53.336,53.848,54.4,54.94,55.5,56.02,56.66,57.288,57.964,58.8$ \\
Bandwidth $(\mathrm{MHz})$ & 300 \\
Elevation & $15-90^{\circ}$ \\
Azimuth & Fixed \\
\hline
\end{tabular}
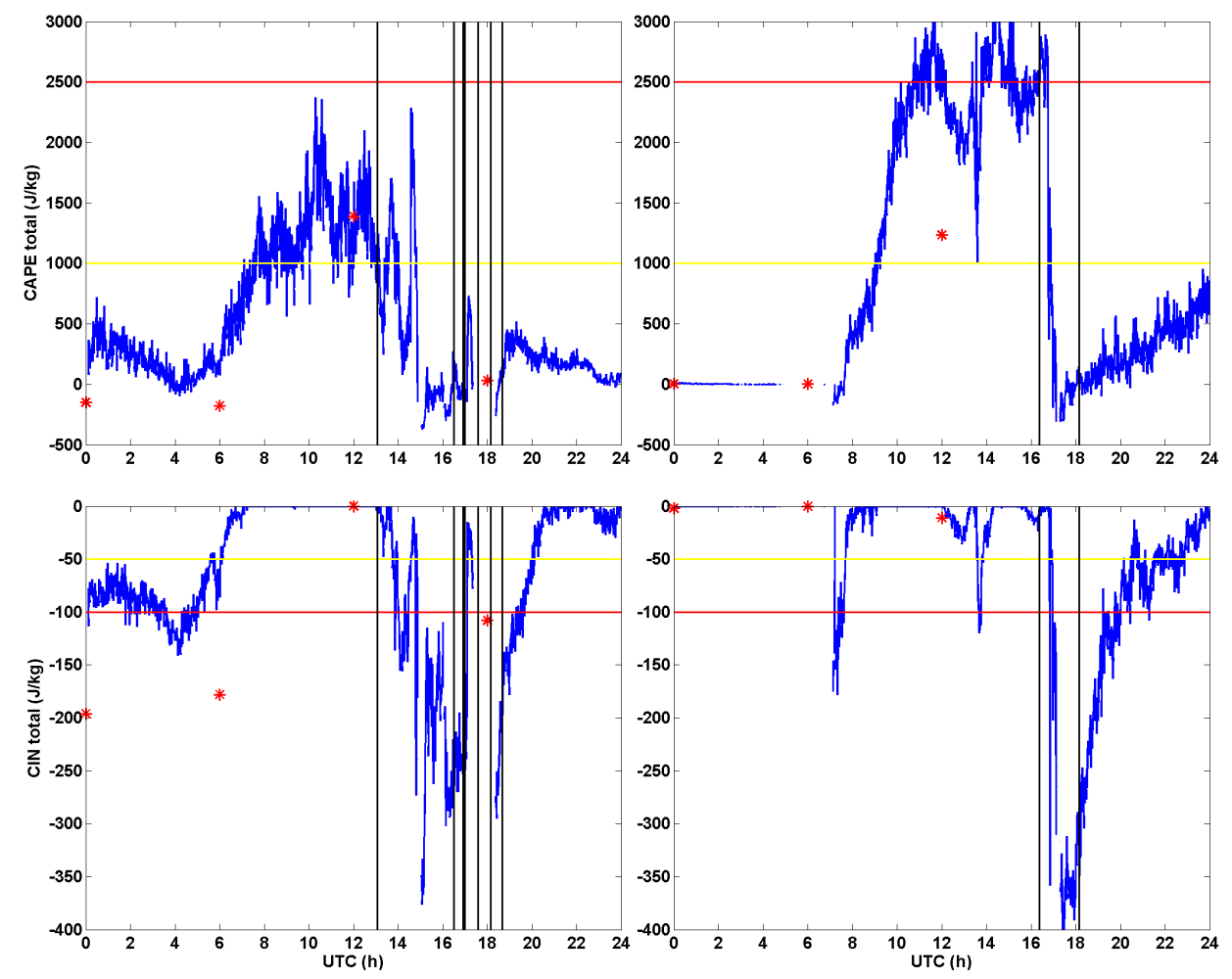

Figure 3. Same as Fig. 2 but for CAPE (top) and CIN (bottom). Yellow and red lines show the thresholds for, respectively, weak and moderate thunderstorm potential (CAPE) and convective inhibition (CIN). Left: 12 August 2010. Right: 15 August 2010.

frequency range, atmospheric thermal emission comes from atmospheric gases (primarily oxygen and water vapour) and hydrometeors (mainly liquid water particles, since ice emission is negligible). The Rayleigh scattering regime applies up to sizes of small raindrops, and in general the scattering contribution is negligible up to light precipitation.

When properly calibrated, a MWRP provides $T_{\mathrm{b}}$ with an absolute accuracy of $\sim 0.3-0.7 \mathrm{~K}$ (Cimini et al., 2003; Löhnert and Maier, 2012; Maschwitz et al., 2013). Atmospheric temperature and humidity profiles can be retrieved from MWRP $T_{\mathrm{b}}$ with a variety of inversion methods, including multivariate regression, neural networks, and variational approaches (Solheim et al., 1998; Löhnert et al., 2004; Hewison, 2007; Cimini et al., 2006, 2010). The actual vertical resolution of MWRP retrievals depends on several factors, including inverse method and atmospheric conditions. In general, the vertical resolution degrades approximately linearly with altitude as half of the height (Cimini et al., 2006). Typical root-mean-square (rms) accuracy for tropospheric temperature and absolute humidity profiles during non-precipitating conditions are, respectively, $\sim 0.5-2.0 \mathrm{~K}$ and $0.2-1.5 \mathrm{~g} \mathrm{~m}^{-3}$ (Güldner and Spänkuch, 2001; Cimini et al., 2011). Accuracy estimates during precipitation including heavy rain have been reported as equal to $3.1 \mathrm{~K}$ and $1.9 \mathrm{~g} \mathrm{~m}^{-3}$ (Xu et al., 2014).

For the data set used in this analysis, the MWRP observed $T_{\mathrm{b}}$ at 22 channels and at 2 elevation angles (zenith and $15^{\circ}$ elevation) and 1 fixed azimuth angle. The microwave radiometer is calibrated using noise diode injection to measure the system gain continuously. The noise diode effective temperature is determined by observing an external cryogenic target less frequently (once every 3 to 6 months). The main characteristics of the MWRP microwave radiometer are reported in Table 1. 


\section{Methodology}

\subsection{MWRP retrieval techniques}

Atmospheric temperature and humidity profiles are retrieved from MWRP observations using any of the above-mentioned inversion methods. The MP-3000A proprietary algorithm deploys a neural networks (NN) method (Solheim et al., 1998), trained with thousands of profiles generated from historical data sets of operational radiosondes. The software offers two versions of the NN retrievals, which may run separately and in parallel, one ingesting zenith observations $(\mathrm{NNz})$ and the other ingesting the available slant observations $(\mathrm{NNa})$. Alternatively, other methods can be applied to retrieve temperature and humidity profiles from MP-3000A data, as multivariate regression or variational approaches. Observation-based multivariate regression (ObsREG), using MWRPs and radiosonde measurements from the past to calculate regression operators, has been successfully demonstrated to remove systematic errors and produce weakly biased retrievals with respect to radiosondes (Güldner and Spänkuch, 2001; Cimini et al., 2006). More recently, the use of a one-dimensional variational (1-DVAR) technique, coupling radiometric observations with outputs from a NWP model, has been demonstrated (Hewison, 2007; Cimini et al., 2006, 2009, 2011). The 1-DVAR method combines observed and forward-modelled $T_{\mathrm{b}}$ with measurement and background error covariance matrices to optimize retrieval accuracy with respect to observation and model uncertainties. The accuracy of temperature and humidity profile retrievals in the boundary layer and lower troposphere it depends primarily on the MWRP observations, while in the upper troposphere depends primarily on the NWP model output. Thus, the 1-DVAR approach avoids the error inherent in methods initialized with local climatology and benefits from recent surface, radiosonde, satellite, radar, and other data assimilated in the local NWP analysis and forecast.

Figure 1 shows the statistical results for water vapour and temperature profiles computed using the above methods as compared with radiosondes profiles. In Fig. 1 are reported the mean difference (MD), standard deviation (SD), and rms difference for simultaneous profiles (from ObsREG, $\mathrm{NNa}, \mathrm{NNz}$, and 1-DVAR), using radiosonde as the reference. These results are obtained in the period May-June 2010 for a continental site at midlatitude, the MOL-RAO in Lindenberg, Germany. Figure 1 shows the results from the 233 cases in which all the data sources (radiosondes and MWRPs) are simultaneously available. All observations during all weather conditions are included in the statistical comparison. Note that the radiosonde observations used for validation are not assimilated into NWP at the time of comparison, so they provide a really independent data set. Concerning temperature profiles, Fig. 1 suggests that both ObsREG and 1-DVAR show a small bias (MD within $1 \mathrm{~K}$ ) relatively to $\mathrm{NNa}$ and $\mathrm{NNz}$ (MD within 3 and $6 \mathrm{~K}$, respectively, for $\mathrm{NNz}$ and $\mathrm{NNa}$ ). Although

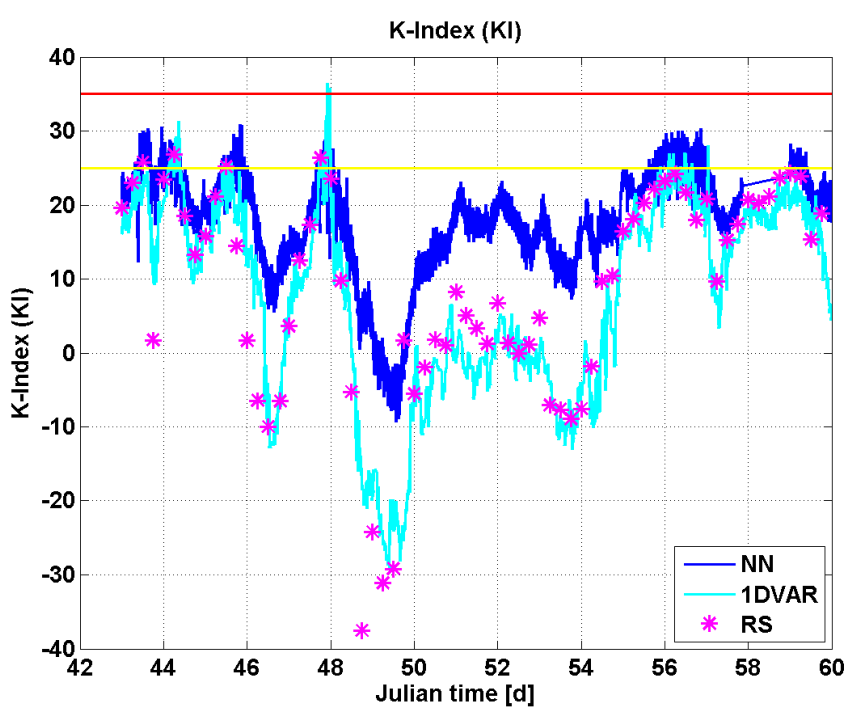

Figure 4. 17-day-long time series of $K$ index in Whistler. $K$ index from radiosondes (RS) and from MWRP NNz and 1-DVAR retrievals is indicated with magenta stars, and a blue and cyan line, respectively. The horizontal yellow and red lines indicate moderate and high thunderstorm potential, respectively.

the methods show similar SD in the boundary layer, this tends to separate for altitudes higher than $1 \mathrm{~km}$ : SD remains within $1 \mathrm{~K}$ up to $10 \mathrm{~km}$ for 1-DVAR, while it increases with height for ObsREG, NNz, and especially NNa. The resulting rms remains within $1 \mathrm{~K}$ up to $10 \mathrm{~km}$ for 1-DVAR, within $2 \mathrm{~K}$ for ObsREG, and within $3 \mathrm{~K}$ for $\mathrm{NNz}$, while it exceeds $6 \mathrm{~K}$ between 2.5 and $4 \mathrm{~km}$ for NNa. Figure 1 confirms that 1-DVAR provides better agreement with radiosondes than other considered methods for temperature profiling, minimizing both the systematic and random errors by benefiting from recent data assimilated in the NWP model. Concerning humidity profiles, Fig. 1 reports similar performances for the four techniques, though ObsREG and 1-DVAR show smaller bias in the $2-4 \mathrm{~km}$ range, and 1-DVAR shows degraded performances in the lowest $1 \mathrm{~km}$ layer. Similar results were obtained for other environmental conditions (Cimini et al., 2011; Ware et al., 2013), specifically for the mountain site at Whistler, Canada.

\subsection{Forecast indices}

Forecast indices are used at various airports and NWS as tools for operational meteorology, e.g. to provide a quantitative and objective way to assist forecasters in issuing weather hazard alerts (Haklander and Van Delden, 2003). There are a number of FIs that have been developed and are currently used, depending upon the particular climatology of various sites. A quite comprehensive review can be obtained from Miller (1972), Peppier (1998), and Haklander and Van Delden (2003). FIs are usually computed from radiosonde profiles of temperature, humidity, and wind (if available). 

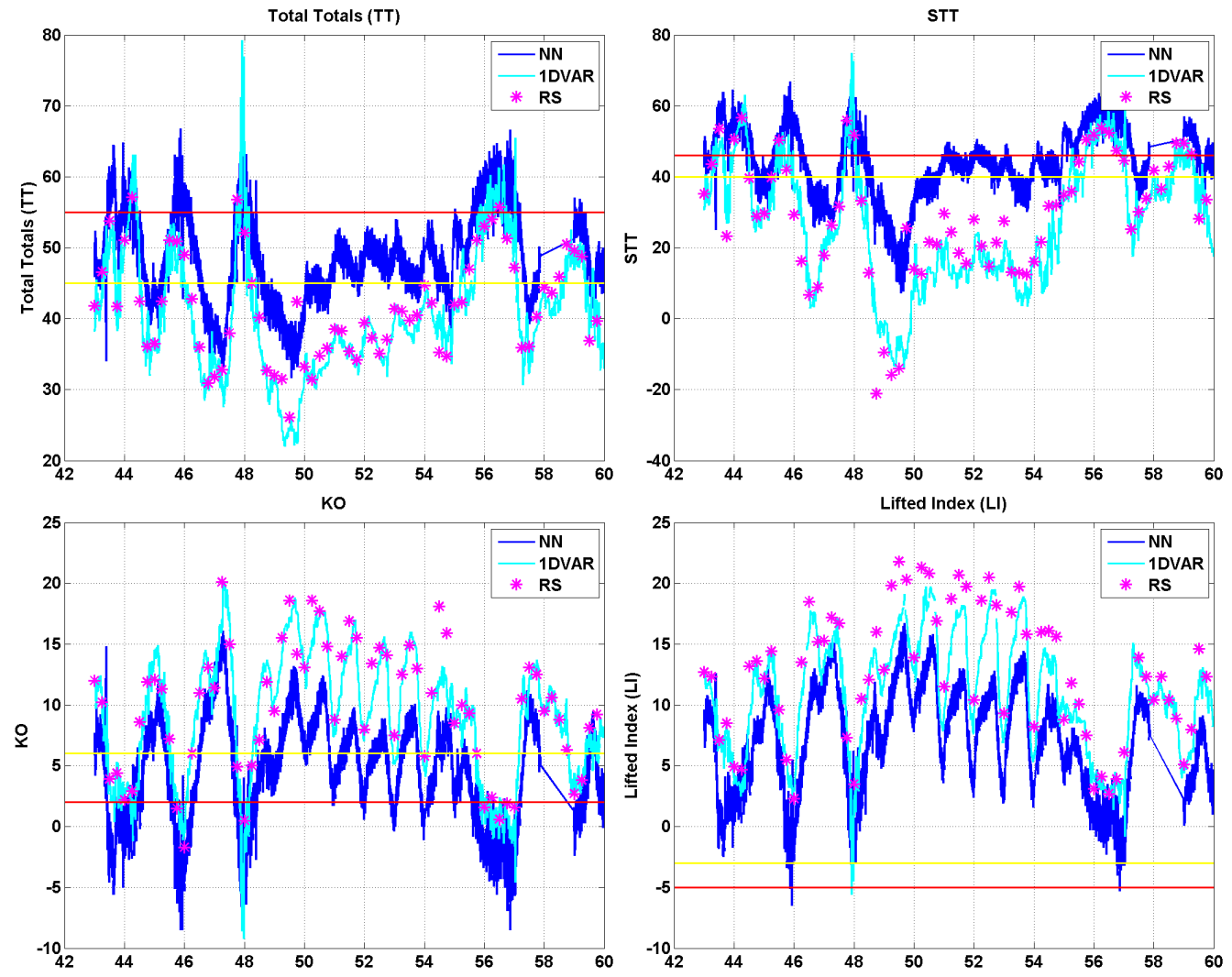

Figure 5. As in Fig. 3 but for (clockwise from top-left panel) total totals, STT, LI, and KO. The horizontal yellow and red lines indicate thresholds for moderate and high potential, respectively.

When only temperature and humidity profiles are available, a reduced set of FIs can be computed. This is the case for PTU (pressure, temperature, relative humidity) radiosondes, which are not equipped for wind estimation, as well as for MWRPs. Therefore, temperature and humidity profiles retrieved by MWRPs may be given in input to forecast tools developed for computing FIs from PTU radiosondes. FIs from temperature and humidity profiles are also estimated from geostationary satellites retrievals (König, 2002; König and de Coning, 2009; de Coning et al., 2011). These satellite FI estimates are produced operationally and cover most of the Earth's surface at some 3-10 km resolution. However, satellite FIs are based on infrared sounding channels, which tend to saturate in the presence of clouds, and thus are only available in clear-sky conditions. Moreover, the reliability of satellite FIs is hampered by the rather coarse vertical resolution of temperature and humidity profile retrievals from geostationary satellites, particularly in the lower troposphere.

More details on the FIs considered in this paper are provided in Appendix A. Note that these simple methods have the advantage of being based on reproduction of actual atmospheric processes, which should be broadly applicable while being relatively easy to understand and implement. The FI values presented in the next sections were computed by processing temperature and humidity profiles with the universal RAwinsonde OBservation (RAOB) program software (www.raob.com). FIs from radiosondes and MWRPs were computed independently. Let us emphasize that FIs from MWRPs are computed from MWRP-retrieved temperature and humidity profiles, i.e. not directly from $T_{\mathrm{b}}$ observations.

Note that it is beyond the scope of this paper to demonstrate the use and the forecast skills of the various FIs. This topic is discussed in the review papers mentioned above (e.g. Haklander and Van Delden, 2003), and it is still the subject of debate within the weather forecast community (e.g. Doswell III and Schultz, 2006). The aim of this paper is to investigate the feasibility of producing good-quality FIs from MWRP observations and to quantify the agreement and correlation with analogous FIs estimated from radiosondes. If the agreement is deemed satisfactory, we shall conclude that MWRPs can deliver additional valuable products that may complement radiosondes, or even supply for the lack thereof, in support of local short-term weather forecasting.

\section{Results}

This section presents the results of computing FIs from MWRP temperature and humidity profiles and their agree- 

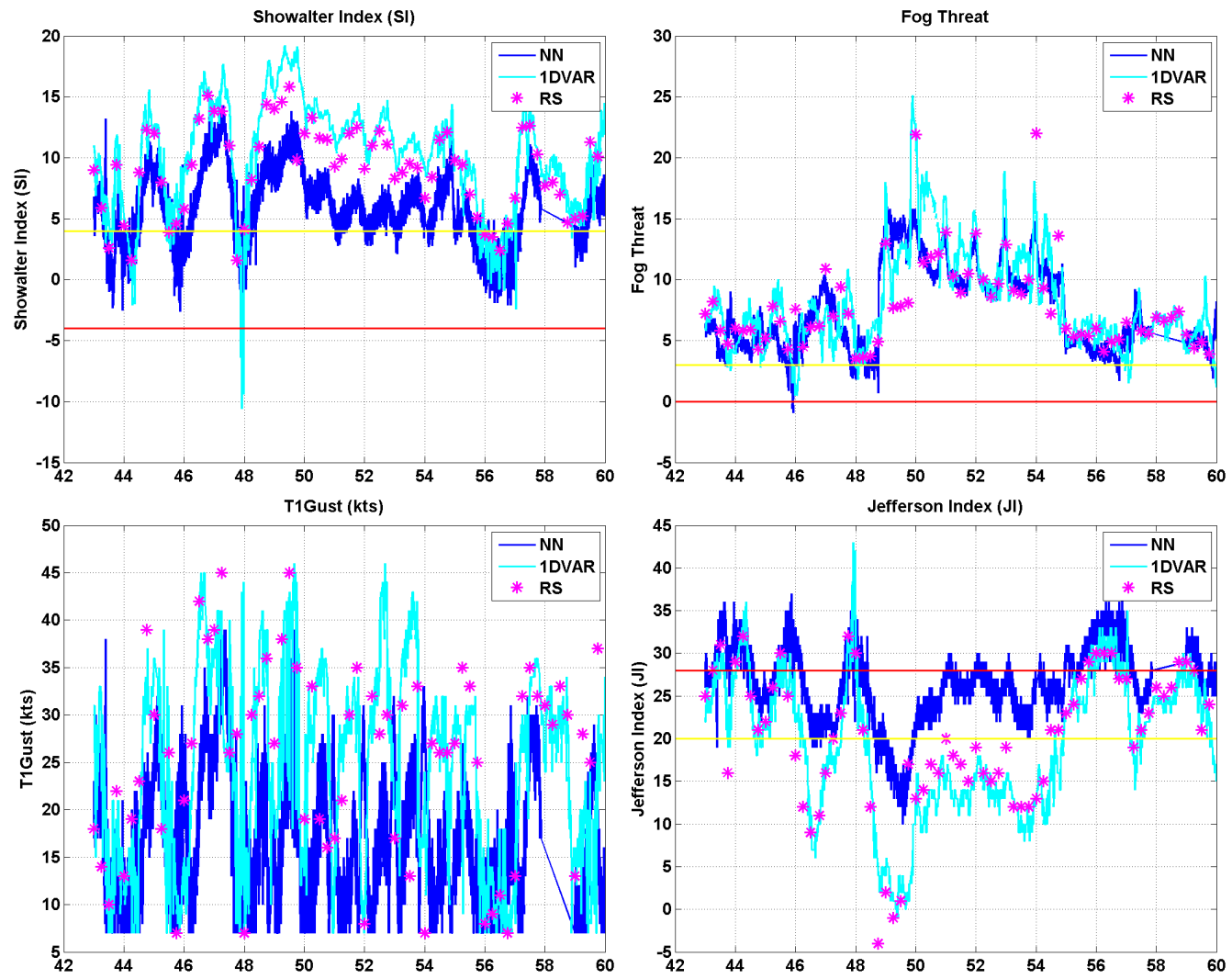

Figure 6. As in Fig. 3 but for (clockwise from top-left panel) Showalter index, fog threat, T1 gust, and Jefferson index. The horizontal yellow and red lines indicate thresholds for moderate and high potential, respectively (where applicable).

ment with the analogous FIs computed from radiosonde profiles. The results are presented for two sites corresponding to different environmental conditions. The MOL-RAO is located at midlatitude $\left(52.17^{\circ} \mathrm{N}, 14.12^{\circ} \mathrm{E}\right)$ and low altitude ( $98 \mathrm{~m}$ above sea level (a.s.l.)), in a flat area in central Europe about $50 \mathrm{~km}$ to the southeast of Berlin, the capital of Germany. Embedded in this countryside are small and medium-sized lakes. The land use is dominated by forest and agricultural fields. Whistler (Canada) is located at midlatitude $\left(50.09^{\circ} \mathrm{N}, 122.98^{\circ} \mathrm{W}\right)$ and relatively high elevation (776 m a.s.l.) in a mountainous environment along the Pacific Ranges of the Coast Mountains in western North America. The quality assessment of the forecast indices in different atmospheric conditions ideally would require data spanning over 1 year and covering all seasons. However, Whistler data include only the 2-week period during the February 2010 Vancouver Winter Olympics. Weather conditions during this time period included multiple days of clear conditions and rain, sleet, and snow days with precipitation rates up to $20 \mathrm{~mm} \mathrm{~h}^{-1}$ (Cimini et al., 2011). Precipitation occurred when southwest winds advected moist maritime air from Vancouver Sound up the Whistler Valley, where it condensed, inflated upper air temperature and humidity, and triggered precipitation (Ware et al., 2013). Conversely, MWRP and ra- diosonde data in Lindenberg are collected operationally 24/7 throughout the year. However, MWRP 1-DVAR retrievals are only available for the summer 2010 as part of a research project. Lindenberg has a moderate midlatitude climate at the transition between marine and continental influences. During summer, the monthly mean temperature varies between 13 and $18^{\circ} \mathrm{C}$, while the average monthly total precipitation is about $60 \mathrm{~mm}$ with $8-9$ average days with precipitation per month. Therefore, our analysis is strictly valid for the atmospheric conditions experienced in those two periods.

Two $24 \mathrm{~h}$ time series of $K$ index as computed from radiosonde and MWRP profiles in Lindenberg are shown in Fig. 2. These are typical continental summertime cases (12 and 15 August 2010), in which convection starts to develop after the sunrise, generating thunderstorms in the afternoon. As explained in Appendix A, the $K$ index is such that the higher the value, the higher the probability of thunderstorms. In particular, empirical thresholds are often used to separate weak $(K$ index $<25 \mathrm{~K})$ from moderate $(25 \mathrm{~K}<K$ index $<35 \mathrm{~K}$ ) and finally strong thunderstorm potential ( $K$ index $>35 \mathrm{~K}$ ). Although it is beyond the scope of this paper to demonstrate the skills of FIs and the applied thresholds, Fig. 2 shows how increasing values of $K$ index correspond to increasing instability, eventually culminating in a thunder- 
Table 2. Statistics of the difference between FIs computed from radiosonde and MWRP retrievals (NNz and 1-DVAR) in Whistler (64 radiosondes). Here are shown average (AVG) FI difference (radiosonde-MWRP), standard deviation (SD), root mean square (rms), and correlation coefficient (COR).

\begin{tabular}{|c|c|c|c|c|c|c|c|c|}
\hline & \multicolumn{4}{|c|}{$\mathrm{NNz}$} & \multicolumn{4}{|c|}{ 1-DVAR } \\
\hline & AVG & SD & $\mathrm{rms}$ & COR & AVG & SD & $\mathrm{rms}$ & COR \\
\hline CAPE $\left(\mathrm{J} \mathrm{kg}^{-1}\right)$ & -235.67 & 207.46 & 326.36 & 0.57 & -49.03 & 87.34 & 102.53 & 0.94 \\
\hline $\mathrm{CIN}\left(\mathrm{J} \mathrm{kg}^{-1}\right)$ & -2.28 & 21.19 & 21.33 & -0.60 & 12.50 & 24.05 & 27.67 & 0.95 \\
\hline Fog threat $\left({ }^{\circ} \mathrm{C}\right)$ & 0.45 & 2.37 & 2.41 & 0.80 & 0.45 & 2.37 & 2.41 & 0.80 \\
\hline Jefferson index $\left({ }^{\circ} \mathrm{C}\right)$ & -6.75 & 5.16 & 8.54 & 0.83 & 1.08 & 3.33 & 3.50 & 0.92 \\
\hline$K$ index $\left({ }^{\circ} \mathrm{C}\right)$ & -10.25 & 9.23 & 13.85 & 0.88 & 1.05 & 6.15 & 6.24 & 0.91 \\
\hline $\mathrm{KO}\left({ }^{\circ} \mathrm{C}\right)$ & 5.41 & 2.28 & 5.91 & 0.91 & 0.60 & 1.79 & 1.89 & 0.94 \\
\hline Lifted index $\left({ }^{\circ} \mathrm{C}\right)$ & 5.91 & 2.36 & 6.41 & 0.91 & 1.76 & 1.64 & 2.41 & 0.96 \\
\hline $\operatorname{MDPI}\left({ }^{\circ} \mathrm{C} \mathrm{kts}^{-1}\right)$ & -0.11 & 0.11 & 0.16 & 0.80 & 0.00 & 0.11 & 0.11 & 0.83 \\
\hline Showalter index $\left({ }^{\circ} \mathrm{C}\right)$ & 3.40 & 1.96 & 3.95 & 0.84 & -1.10 & 1.75 & 2.07 & 0.92 \\
\hline $\operatorname{STT}\left({ }^{\circ} \mathrm{C}\right)$ & -16.13 & 11.35 & 19.82 & 0.81 & 2.36 & 7.54 & 7.91 & 0.91 \\
\hline T1 gust (kts) & 7.71 & 10.82 & 13.32 & 0.24 & 0.15 & 7.79 & 7.79 & 0.70 \\
\hline Thompson index $\left({ }^{\circ} \mathrm{C}\right)$ & -16.17 & 10.85 & 19.58 & 0.87 & -0.73 & 6.19 & 6.23 & 0.94 \\
\hline Total totals $\left({ }^{\circ} \mathrm{C}\right)$ & -7.30 & 3.94 & 8.34 & 0.85 & 1.16 & 3.48 & 3.67 & 0.91 \\
\hline TQ index $\left({ }^{\circ} \mathrm{C}\right)$ & -5.61 & 4.41 & 7.17 & 0.81 & 1.07 & 3.26 & 3.44 & 0.90 \\
\hline
\end{tabular}

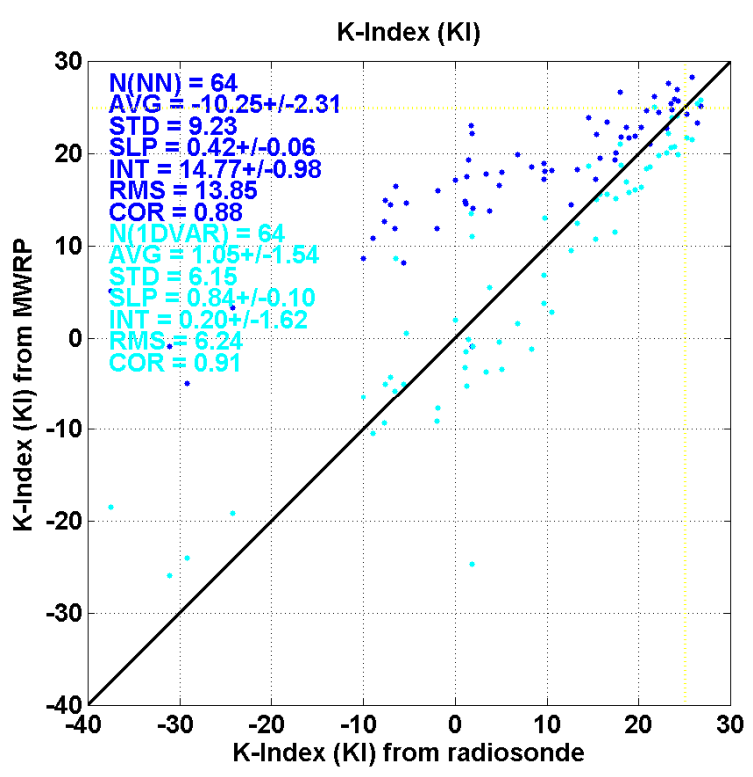

Figure 7. Scatter plot of $K$ index values computed from radiosonde and MWRP-retrieved profiles (NNz in blue, 1-DVAR in cyan) and respective statistics: average (AVG), standard deviation (SD), and root-mean-square (rms) differences, correlation coefficient (COR), slope (SLP), and intercept (INT) of a least-square linear fit. AVG, SD, INT, and rms are in kelvin. SLP and COR are unitless. Numbers after the \pm sign indicate the $95 \%$ confidence interval.

storm. In fact, we see $K$ index values increasing from below the weak-potential threshold in the morning to above the high-potential threshold in the afternoon, and then decaying down in the evening. Multiple thunderstorms were reported near Lindenberg during the afternoon of both days.
These time series suggest that the $K$ index computed from MWRP profiles follows quite reasonably the trend given by the radiosondes, launched 4 times a day. Moreover, the value can be appreciated of the nearly continuous $(\sim 1 \mathrm{~min}$ resolution) $K$ index provided by MWRP with respect to the information provided by the radiosondes at a rather coarse time spacing (6h). For example, considering the trend of $K$ index suggested by the radiosondes between 06:00 and 18:00 UTC of 15 August 2010, the thunderstorm potential seems to be decreasing steadily from nearly strong to weak values. By looking at radiosonde $K$ index only, a forecaster would have missed the rapid increase in instability after 12:00 UTC indicated by the MWRP, which largely overshoot the strong potential and likely generated the thunderstorm reported right after 16:00 UTC.

Similar considerations apply for other FIs related to convective activity, such as convective available potential energy and convective inhibition (CAPE and CIN, respectively; see Appendix A). Figure 3 reports $24 \mathrm{~h}$ time series of CAPE and CIN for the same two cases of Fig. 2. For both cases, the MWRP shows a rapid increase in CAPE between 08:00 and 12:00 UTC, which would have been missed by looking at radiosonde only. On 12 August, CAPE shows a gradual trend of increasing instability until it reaches a peak at 11:00 UTC, i.e. some $2 \mathrm{~h}$ before thunderstorm outbreak, and then drops off quickly. This behaviour is quite typical, as reported by Wagner et al. (2008). Correspondingly, low CIN values are reported between 07:00 and 13:00 UTC, while convective inhibition becomes stronger right after the outbreak. On $15 \mathrm{Au}-$ gust, the MWRP reports large CAPE values $\left(>2500 \mathrm{~J} \mathrm{~kg}^{-1}\right.$ ) starting from 11:00 UTC, i.e. more than $5 \mathrm{~h}$ before the thunderstorm outbreak. A sharp CAPE drop is detected after 

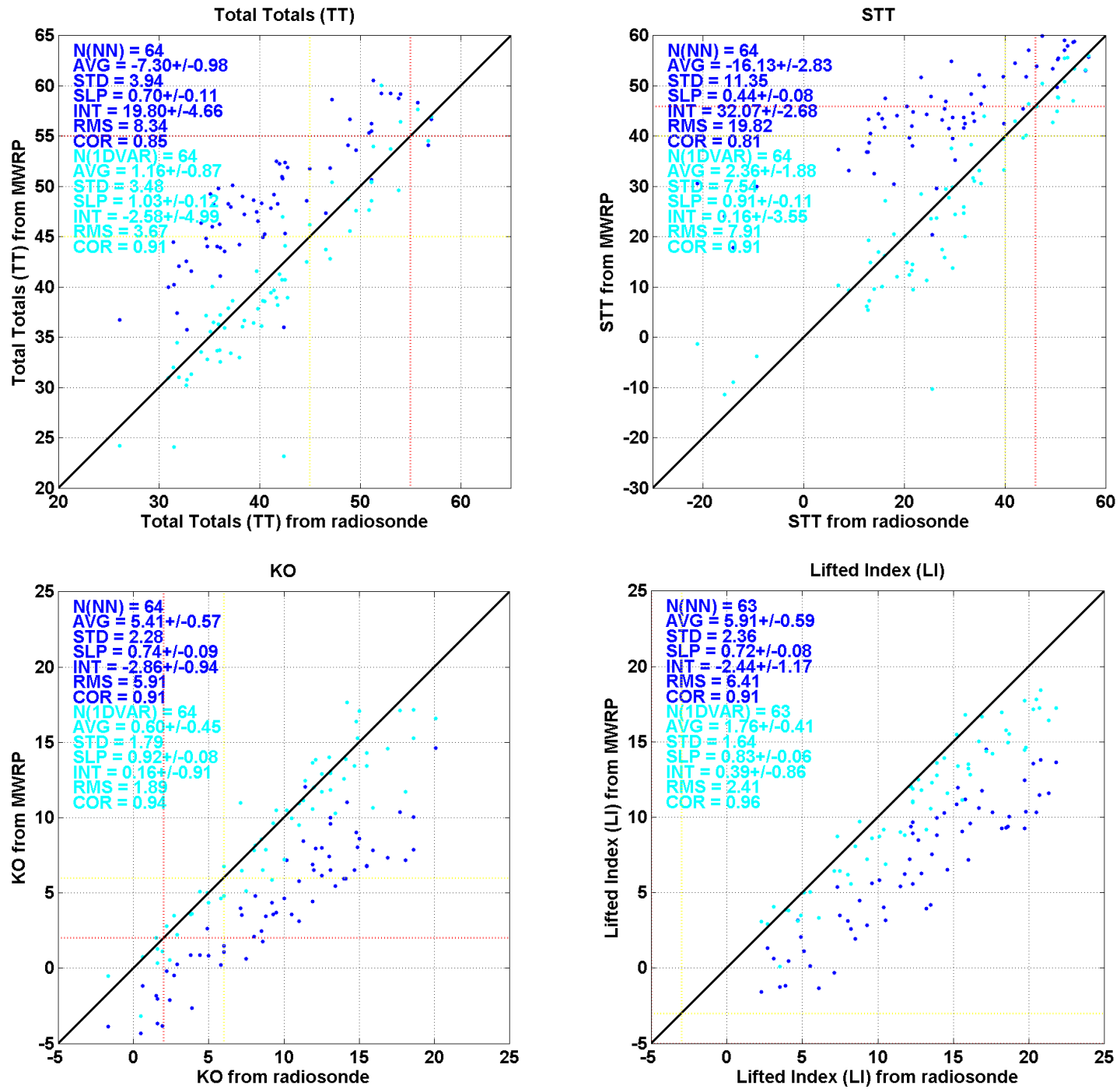

Figure 8. As in Fig. 6 but for (clockwise from top-left panel) total totals, STT, KO, and lifted index. Dotted yellow and red lines indicate thresholds for moderate and high potential, respectively (where applicable).

the outbreak, corresponding to strong convective inhibition (large negative CIN values), indicating the re-establishment of stable conditions for the rest of the day.

For the present analysis, a total of 61 days of MWRP data and 244 radiosonde ascents at $6 \mathrm{~h}$ intervals are used for Lindenberg, while a total of 17 days of MWRP data and 68 radiosonde ascents at $6 \mathrm{~h}$ intervals are available for Whistler. Figure 4 shows the 17-day time series of $K$ index in Whistler for the period 12-28 February 2010 (Julian day 43-59). In this period the $K$ index computed by radiosondes always reported weak to moderate thunderstorm potential, which is reasonable for Whistler during wintertime. However, the $K$ index computed from MWRP retrievals shows a pick exceeding the high-potential threshold on 16 February (Julian day 47), which was followed by a snowstorm (Cimini et al., 2011; Ware et al., 2013). Other snowstorms were experi- enced during the periods $12-15$ and 24-27 February (Julian day 43-46 and 55-58), in which the $K$ index from both radiosondes and MWRPs occasionally exceeds the moderatepotential threshold. Note that the trend of $K$ index indicated by the radiosonde is followed better by the 1-DVAR than the NNz retrievals. This is especially evident during clearsky and fair-weather conditions (as for example between Julian day 49 and 55). In fact, these conditions were associated with decreased moisture at $850-700 \mathrm{mb}$ levels and increased static stability between 850 and $500 \mathrm{mb}$, causing extremely low values of $K$ index. This is a direct consequence of the situation pictured in Fig. 1, which shows lower systematic and random errors for 1-DVAR than for $\mathrm{NNz}$ retrievals in the upper air, where the $850-500 \mathrm{mb}$ pressure levels reside. Note also that during clear nocturnal conditions the MWR observations were particularly useful to detect a cold bias in 

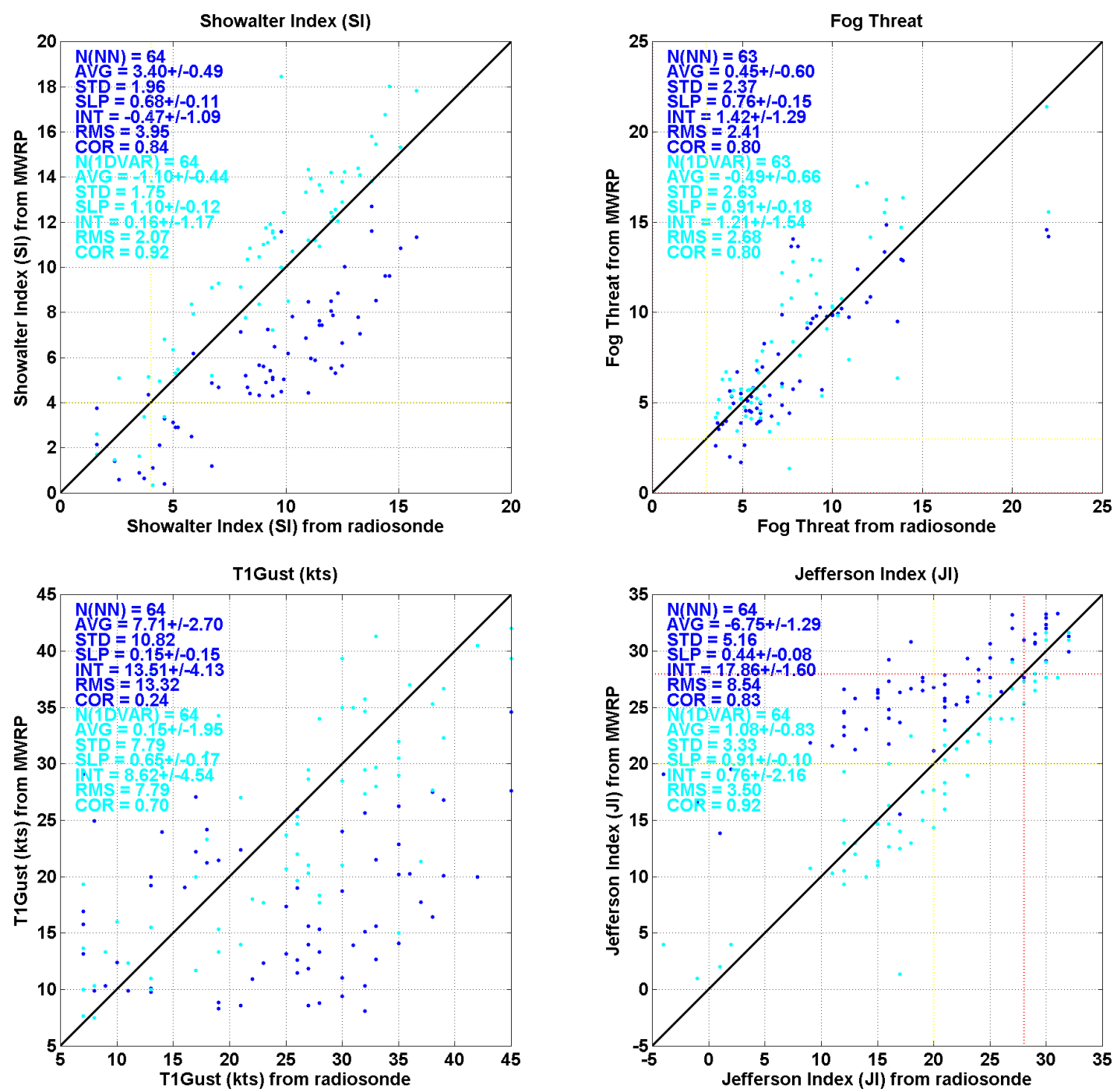

Figure 9. As in Fig. 6 but for (clockwise from top-left panel) Showalter index, fog threat, T1 gust, and Jefferson index. Dotted yellow and red lines indicate thresholds for moderate and high potential, respectively (where applicable).

the analysis boundary layer temperature (Ware et al., 2013), which were used as initial condition for 1-DVAR. This confirmed the large uncertainty associated with gridded analysis in the nocturnal boundary layer (Hart et al., 1998; Hart and Forbes, 1999).

Similarly, Figs. 5 and 6 show the time series for the same period but for other forecast indices, namely the total totals, STT, KO, lifted index, Showalter index, fog threat, T1 gust, and finally Jefferson index. Note that, as detailed in Appendix A, some FIs have an inverted trend; i.e. the lower the value, the higher the potential. For total totals, KO, Showalter index, lifted index, STT, and Jefferson index the same considerations for Fig. 4 apply: the trend indicated by radiosondes is well captured by the MWRP estimates, specially those computed from 1-DVAR retrievals, both for the diurnal and extra-diurnal cycles. More in detail, the lifted index and
Showalter index closely resemble the behaviour discussed above for the $K$ index, while some other FIs - namely the total totals, KO, STT, and Jefferson index - exceed the highpotential threshold for all the three periods in which snowstorms happened.

For other two of the considered FIs, specifically fog threat and T1 gust, MWRP estimates again follow quite well the trend indicated by radiosondes, but the difference between 1DVAR and NNz is difficult to appreciate. The fog threat values indicate low potential throughout the period, except for 15 February (Julian day 46), a few hours before a sudden fog event occurred. However, a few other fog/mist events were reported (e.g. Julian days 43, 45, 48, 59), in correspondence to which the fog threat shows values from low to moderate potential. The T1 gust shows maximum wind gust up to 45 
knots $\left(\sim 23 \mathrm{~m} \mathrm{~s}^{-1}\right)$, though reported winds at the radiosonde launching site did not exceed 20 knots $\left(\sim 10 \mathrm{~m} \mathrm{~s}^{-1}\right)$.

In order to make a quantitative statement on the agreement of the considered FI as computed from radiosonde and MWRP-retrieved profiles, we process the data in order to match the independent data sets and compute statistical scores, such as the average (AVG), SD, and rms differences, the correlation coefficient (COR), and finally the slope (SLP) and intercept (INT) of a least-square linear fit. The statistical scores for $K$ index in Whistler are summarized in Fig. 7. For higher values ( $K$ index $>15$ ), it is evident that both $\mathrm{NNz}$ and 1-DVAR agree fairly well with the values computed from radiosondes. For lower values the 1-DVAR gives much better agreement than $\mathrm{NNz}$, as anticipated above. Overall, the comparison in Whistler of $K$ index computed from 1-DVAR temperature and humidity retrievals with $K$ index computed from radiosonde profiles shows rms error within $6.1 \mathrm{~K}$ (less than $10 \%$ of the total range) with a correlation coefficient better than 0.9 . With respect to $\mathrm{NNz}$ retrievals, 1-DVAR reduces significantly both the systematic (AVG roughly from 10 to $1 \mathrm{~K}$ ) and the random (SD by a factor of $1.5, \mathrm{rms}$ by a factor of 2) error components. Note that the results for $\mathrm{NNz}$ are still fairly good ( 0.88 correlation) and tend to agree with 1 -DVAR for higher values, where the $K$ index is more interesting for forecasting purposes.

Similarly, Figs. 8 and 9 show the scatter plots and statistical scores for the other forecast indices. For Jefferson index, total totals, KO, Showalter index, lifted index, and STT similar considerations as for $K$ index apply; i.e. the comparison between FIs from radiosonde and MWRP retrievals results in (a) a significant improvement of the statistical scores for 1DVAR with respect to $\mathrm{NNz}$, and (b) correlation coefficients better than 0.9 and rms within $10 \%$ of the range (considering 1-DVAR). As for the $K$ index, results for $\mathrm{NNz}$ are still fairly good (correlation between 0.8 and 0.9 depending on FI) and tend to agree with 1-DVAR in the most significant range. For the fog threat and T1 gust, the correlation coefficients are much lower (respectively 0.8 and 0.7 , considering 1-DVAR) and the rms exceeds $10 \%$ of the range (respectively 12 and $19 \%$, considering 1-DVAR). The improvement brought by $1-$ DVAR with respect to $\mathrm{NNz}$ is significant for $\mathrm{T} 1 \mathrm{gust}$ (a factor of 1.5 for SD and rms, a factor $\sim 3$ for correlation), while it becomes negligible for the fog threat. The latter result can be explained by looking at the similar results for NNz and 1DVAR in Fig. 1 for the lower levels, which mainly determine the value of the fog threat index.

The statistics of the difference between FIs computed from radiosonde and MWRP retrievals in Whistler are summarized in Table 2 . In addition to the FIs discussed above, Table 2 shows the results for five more FIs, namely the CAPE, the CIN, the microburst day potential index (MDPI), the Thompson index, and finally the TQ index. Note that CAPE and CIN are not always determined by definition, and thus the results are obtained from a smaller data set. For CAPE, the 1-DVAR retrievals show 0.94 correlation coefficient and

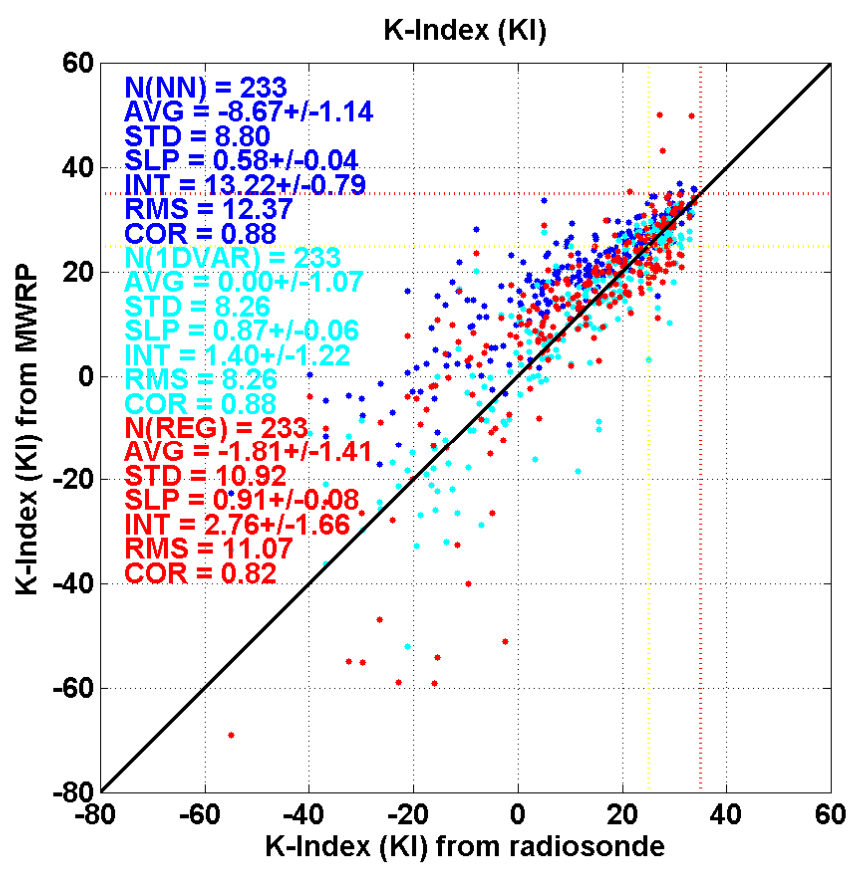

Figure 10. Scatter plot of $K$ index values computed from radiosonde and MWRP-retrieved profiles (NNz in blue, 1-DVAR in cyan, REG in red) and respective statistics: average (AVG), standard deviation (SD), and root-mean-square (rms) differences, correlation coefficient (COR), slope (SLP) and intercept (INT) of a least-square linear fit. AVG, SD, INT, and rms are in kelvin. SLP and COR are unitless. Numbers after the \pm sign indicate the $95 \%$ confidence interval.

$102.5 \mathrm{~J} \mathrm{~kg}^{-1} \mathrm{rms}$, with an improvement factor of 1.6 and 4.8 , respectively, with respect to NNz. For CIN, the 1-DVAR retrievals show 0.95 correlation coefficient and $12.50 \mathrm{~J} \mathrm{~kg}^{-1}$ rms, while NNz shows negative correlation. For MDPI, results are similar for $\mathrm{NNz}$ and 1-DVAR retrievals, showing $0.80-0.83$ correlation coefficient, respectively. For Thompson index and TQ index, 1-DVAR retrievals show correlation coefficient exceeding 0.9 and rms within $10 \%$ of the total range, somewhat better than the NNz retrievals. Thus, similarly to other FIs, CAPE, CIN, MDPI, Thompson index, and TQ index show good correlation between radiosondes and MWRP estimates (either NNz or 1-DVAR), with a tangible improvement for 1-DVAR with respect to NNz.

Similarly, Figs. 10-12 and Table 3 show the results for the analysis at the other site, MOL-RAO in Lindenberg. At MOL-RAO, four types of MWRP retrievals are available, as already seen in Fig. 1. FIs are computed from three of those MWRP retrievals (NNz, 1-DVAR, and ObsREG), and then compared to the FIs computed from radiosondes. Figure 10 shows the results for KI, for which the three MWRP retrievals agree fairly well, with $0.81-0.88$ (ObsREG and NNz/1-DVAR, respectively) correlation coefficient with respect to radiosonde values. Figures 11 and 12 show the results for total totals, STT, KO, lifted index, Showalter in- 

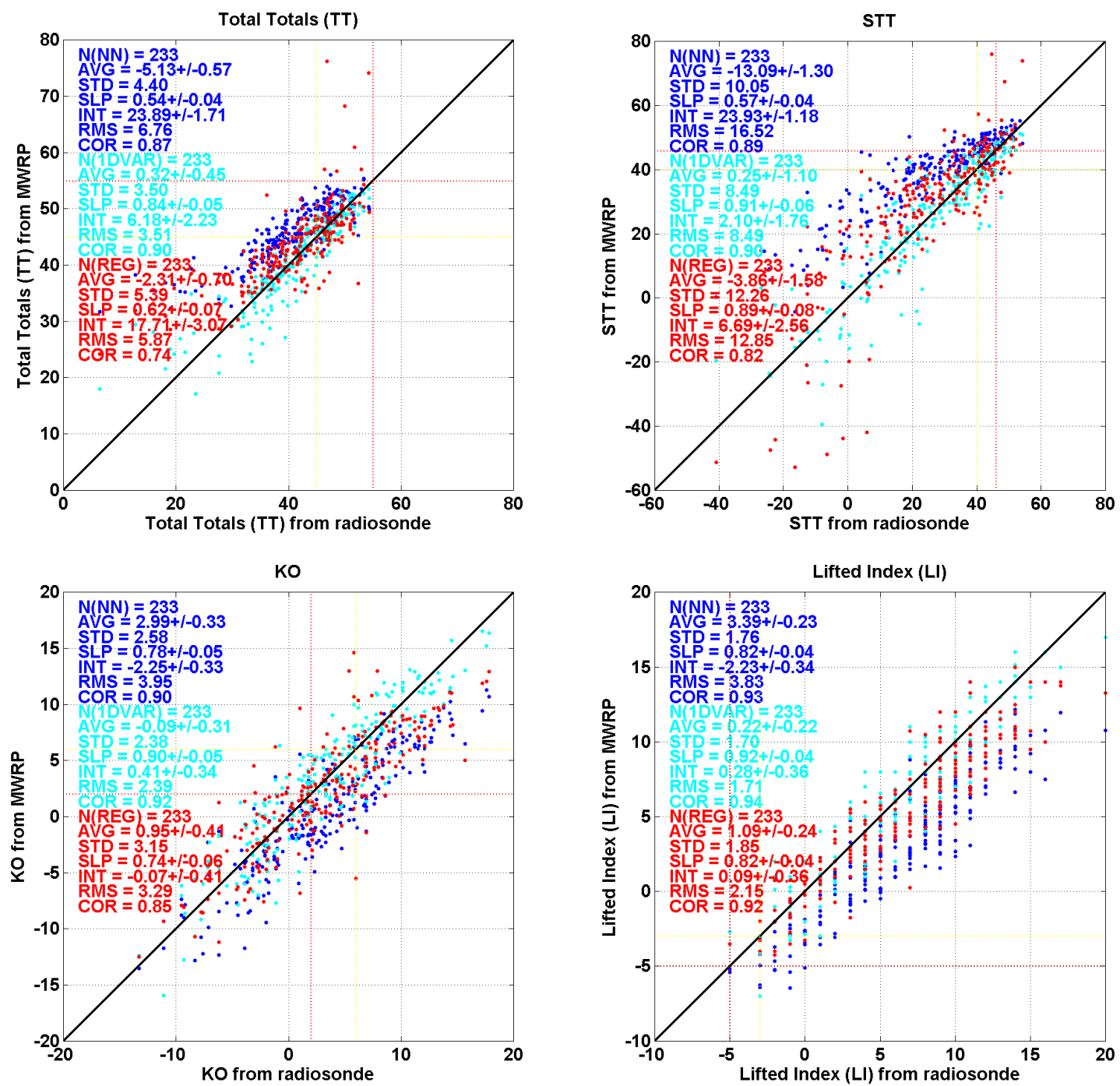

Figure 11. As in Fig. 9 but for (clockwise from top-left panel) total totals, STT, KO, lifted index. Dotted yellow and red lines indicate thresholds for moderate and high potential, respectively (where applicable).

dex, fog threat, T1 gust, and Jefferson index. These results are consistent with the ones in Whistler for the most part. In terms of correlation coefficient, 1-DVAR retrievals usually outperform the other two, though the differences are less significant than in Whistler. However, 1-DVAR shows the lowest correlation of the three retrievals for two FIs (CAPE and fog threat), while it shows lower correlation than $\mathrm{NNz}$ for the TQ index. Note that CAPE and CIN show lower correlation than other convective FIs. This may be caused by the different (smaller) data set available for computing the statistics and/or to the MWRP moderate vertical resolution causing uncertainties in the location of the integral boundaries.

Finally, Table 4 presents a summary of the comparison of all FIs as computed from radiosondes and MWRPs for the three retrieval methods and the two data sets considered in this analysis. As a common normalized statistical measure we adopt the normalized rms (NRMS), i.e. rms divided by the range of observed values. NRMS is deemed appropriate to compare all the FIs as it is little sensitive to the occurrence of 0 values (often occurring for CAPE, CIN, $K$ index, $\mathrm{KO}$, etcetera). Table 4 shows that NRMS is generally smaller for Lindenberg than for Whistler. In Whistler, NRMS ranges from 8 to $35 \%$ for all FIs but CAPE and CIN, though the latter are affected by a much lower sample size. In Lindenberg, NRMS ranges from 7 to $22 \%$, depending upon FI (except for CIN with ObsREG). Overall, 1-DVAR shows the best agreement, with NRMS ranging from 7 to $17 \%$.

\section{Summary and conclusions}

Forecast indices based on radiosonde soundings have been developed over many decades as local weather prediction 

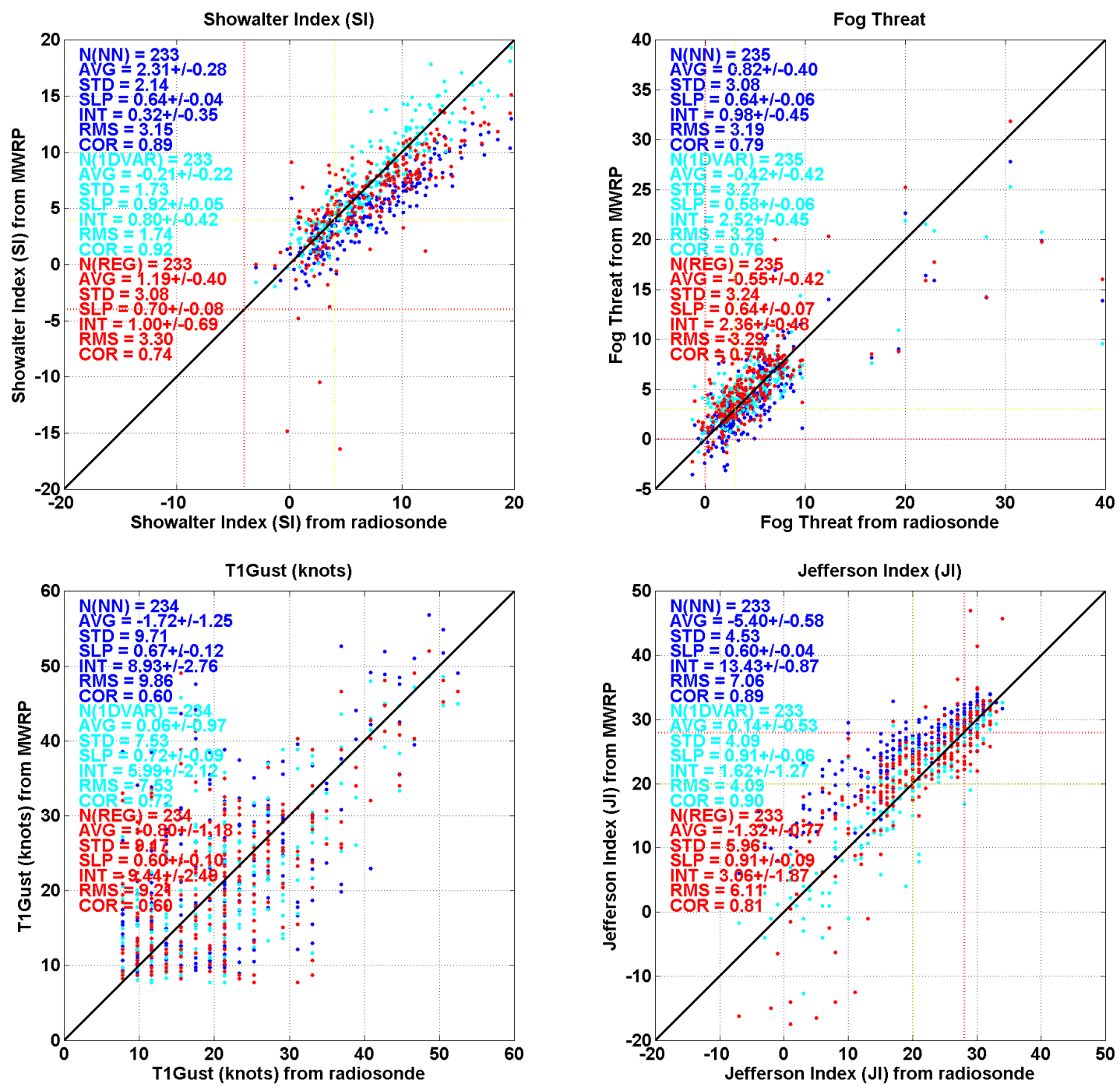

Figure 12. As in Fig. 9 but for (clockwise from top-left panel) Showalter index, fog threat, T1 gust, and Jefferson index. Dotted yellow and red lines indicate thresholds for moderate and high potential, respectively (where applicable).

tools. However, FIs typically lose their value during 6-hour and longer intervals between traditional radiosonde soundings. Continuous tropospheric thermodynamic profiles can be retrieved on a minute timescale from a ground-based MWRP working in the $20-60 \mathrm{GHz}$ range. FIs developed for radiosonde TPU profiles can be derived from the MWRP thermodynamic profiles. The present analysis demonstrates good agreement between FIs derived from MWRP and radiosonde soundings. The analysis is performed for two midlatitude sites: one residing in a low-elevation, flat rural area in central Europe (Lindenberg, Germany) and the other in a mountainous environment along the Pacific Ranges of the Coast Mountains in western North America (Whistler, Canada).

Though it would be ideal to extend the analysis presented here to a larger data set, possibly covering all different seasons, our analysis revealed that
- there is good agreement between MWRP- and radiosonde-derived FIs at both sites, with correlation coefficients usually exceeding 0.8 ;

- FIs derived from 1-DVAR retrievals usually outperform neural network and observation-based regression retrievals in terms of correlation, mean, and random difference with respect to FI values derived from radiosondes;

- FI time series derived from MWRP retrievals provide promising new tools for local high-impact weather prediction (Madhulatha et al., 2013) based on uninterrupted surveillance of local tropospheric thermodynamics in all weather conditions (Cimini et al., 2011; Ware et al., 2013; Xu et al., 2014), capturing the entire diurnal cycle and providing fresh and timely data to forecasters. 
Table 3. As in Table 2 but for Lindenberg (233 radiosondes). Average (AVG) FI difference (radiosonde-MWRP), standard deviation (SD), and correlation coefficient (COR) are shown.

\begin{tabular}{|c|c|c|c|c|c|c|c|c|c|}
\hline & \multicolumn{3}{|c|}{$\mathrm{NNz}$} & \multicolumn{3}{|c|}{ 1-DVAR } & \multicolumn{3}{|c|}{ ObsREG } \\
\hline & AVG & SD & COR & AVG & SD & COR & AVG & SD & COR \\
\hline CAPE $\left(\mathrm{J} \mathrm{kg}^{-1}\right)$ & -217.39 & 306.68 & 0.72 & -3.38 & 215.39 & 0.76 & 24.58 & 224.78 & 0.82 \\
\hline $\mathrm{CIN}\left(\mathrm{J} \mathrm{kg}^{-1}\right)$ & -17.46 & 46.32 & 0.74 & -8.23 & 40.80 & 0.73 & 19.97 & 165.17 & 0.21 \\
\hline Fog threat $\left({ }^{\circ} \mathrm{C}\right)$ & 0.82 & 3.08 & 0.79 & -0.42 & 3.27 & 0.76 & -0.55 & 3.24 & 0.77 \\
\hline Jefferson index $\left({ }^{\circ} \mathrm{C}\right)$ & -5.40 & 4.53 & 0.89 & 0.14 & 4.09 & 0.90 & -1.32 & 5.96 & 0.81 \\
\hline$K$ index $\left({ }^{\circ} \mathrm{C}\right)$ & -8.67 & 8.80 & 0.88 & 0.00 & 8.26 & 0.88 & -1.81 & 10.92 & 0.82 \\
\hline $\mathrm{KO}\left({ }^{\circ} \mathrm{C}\right)$ & 2.99 & 2.58 & 0.90 & -0.09 & 2.38 & 0.92 & 0.95 & 3.15 & 0.85 \\
\hline Lifted index $\left({ }^{\circ} \mathrm{C}\right)$ & 3.39 & 1.76 & 0.93 & 0.22 & 1.70 & 0.94 & 1.09 & 1.85 & 0.92 \\
\hline $\operatorname{MDPI}\left({ }^{\circ} \mathrm{C} \mathrm{kts}{ }^{-1}\right)$ & -0.04 & 0.14 & 0.83 & 0.03 & 0.11 & 0.90 & 0.04 & 0.19 & 0.68 \\
\hline Showalter index $\left({ }^{\circ} \mathrm{C}\right)$ & 2.31 & 2.14 & 0.89 & -0.21 & 1.73 & 0.92 & 1.19 & 3.08 & 0.74 \\
\hline STT $\left({ }^{\circ} \mathrm{C}\right)$ & -13.09 & 10.05 & 0.89 & 0.25 & 8.49 & 0.90 & -3.86 & 12.26 & 0.82 \\
\hline T1 gust (kts) & -1.72 & 9.71 & 0.60 & 0.06 & 7.53 & 0.72 & -0.80 & 9.17 & 0.60 \\
\hline Thompson index $\left({ }^{\circ} \mathrm{C}\right)$ & -12.04 & 9.35 & 0.91 & -0.20 & 8.60 & 0.90 & -2.87 & 11.27 & 0.85 \\
\hline Total totals $\left({ }^{\circ} \mathrm{C}\right)$ & -5.13 & 4.40 & 0.87 & 0.32 & 3.50 & 0.90 & -2.31 & 5.39 & 0.74 \\
\hline TQ index $\left({ }^{\circ} \mathrm{C}\right)$ & -4.07 & 3.96 & 0.87 & 0.42 & 3.83 & 0.85 & -0.93 & 4.35 & 0.80 \\
\hline
\end{tabular}

Table 4. Summary of normalized rms (NRMS) difference (i.e. rms divided by the range of observed values) between the FIs computed from radiosonde and MWRP retrievals, for all the retrieval methods and data sets given in Tables $2-3$. NRMS is expressed in percentage values.

\begin{tabular}{|c|c|c|c|c|c|}
\hline & \multicolumn{2}{|c|}{$\mathrm{NNz}$} & \multicolumn{2}{|c|}{ 1-DVAR } & \multirow{2}{*}{$\begin{array}{c}\text { ObsREG } \\
\text { Lindenberg }\end{array}$} \\
\hline & Lindenberg & Whistler & Lindenberg & Whistler & \\
\hline CAPE & 15.20 & 135.42 & 8.70 & 42.54 & 9.13 \\
\hline CIN & 13.08 & 64.44 & 10.96 & 83.86 & 43.78 \\
\hline Fog threat & 7.77 & 13.03 & 8.03 & 14.47 & 8.02 \\
\hline Jefferson index & 17.22 & 23.74 & 9.99 & 9.73 & 14.90 \\
\hline$K$ index & 13.92 & 21.55 & 9.30 & 9.71 & 12.46 \\
\hline KO & 12.71 & 27.11 & 7.67 & 8.67 & 10.58 \\
\hline Lifted index & 15.30 & 32.87 & 6.84 & 12.36 & 8.59 \\
\hline MDPI & 10.87 & 17.76 & 8.75 & 11.85 & 14.76 \\
\hline Showalter index & 13.89 & 27.83 & 7.66 & 14.59 & 14.55 \\
\hline STT & 17.37 & 25.51 & 8.93 & 10.18 & 13.51 \\
\hline T1 gust & 22.05 & 35.07 & 16.85 & 20.51 & 20.59 \\
\hline Thompson index & 13.51 & 25.77 & 7.62 & 8.20 & 10.29 \\
\hline Total totals & 14.12 & 26.91 & 7.33 & 11.84 & 12.25 \\
\hline TQ index & 12.67 & 24.74 & 8.58 & 11.86 & 9.90 \\
\hline
\end{tabular}

Therefore, we conclude that MWRP retrievals are able to deliver valuable FIs, with the certain advantage (with respect to radiosondes) of nearly continuous updates. FI time series are promising new tools for high-impact local weather forecasting, complementing and augmenting 6/12 $\mathrm{h}$ indices derived from radiosonde soundings. 


\section{Appendix A: Definitions of forecast indices}

In this appendix we summarize the definitions of the forecast indices considered in our analysis. In the following definitions, $T_{\mathrm{xxx}}$ is the temperature at the pressure level $\mathrm{xxx}$ (in $\mathrm{mb}), \mathrm{Td}_{\mathrm{xxx}}$ is dew point temperature, $\theta e_{\mathrm{xxx}}$ is the equivalent potential temperature, and $\theta_{\mathrm{WBxxx}}$ is the wet bulb potential temperature at the same pressure level. The forecast index definitions below were extracted from review papers (Peppier, 1998; Haklander and Van Delden, 2003; de Coning et al., 2011) as well as from American Meteorological Society glossary (AMS, 2013) and RAOB software manual. According to Haklander and Van Delden (2003), the various forecast indices are a combination of three types, the first accounting for pure conditional instability, the second accounting for pure latent instability, and the third accounting for pure potential instability of certain atmospheric layers. In our analysis, we have considered at least one for each type. All temperatures are expressed in ${ }^{\circ} \mathrm{C}$, unless otherwise indicated.

\section{A1 CAPE}

The convective available potential energy (CAPE) defines the maximum energy available to an ascending air parcel, and it is often used to indicate instability and the possibility of thunderstorms. CAPE is also referred to as positive buoyancy. There exist many different definitions of CAPE in the literature (Haklander and Van Delden, 2003). Here, CAPE is calculated by integrating vertically the local buoyancy of a parcel (expressed introducing the virtual temperature of the parcel $T v_{p}$ and that of the environment $T v_{e}$ ) from the level of free convection (LFC) to the equilibrium level (EL):

$\mathrm{CAPE}=-R_{\mathrm{d}} \int_{\text {LFC }}^{\mathrm{EL}}\left(\mathrm{Tv}_{\mathrm{p}}-\mathrm{T}_{\mathrm{e}}\right) \mathrm{d}(\ln p)$,

where $R_{\mathrm{d}}=287.05 \mathrm{~J} \mathrm{~kg}^{-1} \mathrm{~K}^{-1}$ is the gas constant for dry air and CAPE is measured in joules per kilogram of air $\left(\mathrm{J} \mathrm{kg}^{-1}\right)$. Any value greater than $0 \mathrm{~J} \mathrm{~kg}^{-1}$ indicates instability and the possibility of thunderstorms. CAPE values between 1000 and $2500 \mathrm{~J} \mathrm{~kg}^{-1}$ typically qualify as moderate. Note that CAPE is defined only if atmospheric conditions allow LFC and EL to exist.

\section{A2 CIN}

The convective inhibition (CIN) indicates the amount of energy required to overcome the negatively buoyant energy the environment exerts on an air parcel. Conceptually, CIN is the opposite of CAPE (see above) and is also referred to as negative buoyancy. Here, CIN is calculated from the surface (Srf) to the equilibrium level:

$\mathrm{CIN}=-R_{\mathrm{d}} \int_{\text {Srf }}^{\mathrm{EL}}\left(\operatorname{Tv}_{\mathrm{p}}-\mathrm{Tv}_{\mathrm{e}}\right) \mathrm{d}(\ln p)$.
CIN is expressed as a negative energy value. Typically, high absolute CIN values correspond to stable conditions and indicate little likelihood of thunderstorm development. In general, CIN values between 0 and $-50 \mathrm{~J} \mathrm{~kg}^{-1}$ indicate weak convective inhibition. CIN values of $-100 \mathrm{~J} \mathrm{~kg}^{-1}$ or less indicate strong convective inhibition.

\section{A3 Fog threat}

The fog threat (FT) index indicates the potential for radiation fog and is based on the definition of fog point (FP), which is the temperature at which radiation fog will form. The fog point is determined by following the saturation mixing ratio line from the dew point curve at the lifting condensation level (LCL) to the surface temperature. Then, the fog threat is given by the difference of the wet bulb potential temperature at $850 \mathrm{mb} \theta_{\mathrm{WB} 850}$ and the fog point computed as above:

$\mathrm{FT}=\theta_{\mathrm{WB} 850}-\mathrm{FP}$.

The potential for radiation fog is low for FT $>3$, while it becomes high for FT $<0$.

\section{A4 Jefferson index}

The Jefferson index (JI) was designed originally for maritime and arid areas (Haklander and Van Delden 2003, and references therein). JI is defined as

$\mathrm{JI}=1.6 \times \theta_{\mathrm{WB} 850}-T_{500}-0.5 \times\left(T_{700}-\mathrm{Td}_{700}\right)-8$.

Non-frontal thunderstorms can be expected for values above 28. Significant showers with thunderstorm are expected for values above 30 .

\section{A5 $K$ index}

The $K$ index is due to George (1960) and is defined by

$\mathrm{KI}=\left(T_{850}-T_{500}\right)+\mathrm{Td}_{850}-\left(T_{700}-\mathrm{Td}_{700}\right)$.

The first term is the lapse rate, while the second and third are related to the moisture between 850 and $700 \mathrm{mb}$, and are strongly influenced by the temperature-dewpoint spread at the $700 \mathrm{mb}$ level. The $K$ index increases with decreasing static stability between 850 and $500 \mathrm{hPa}$, increasing moisture at $850 \mathrm{hPa}$, and increasing relative humidity at $700 \mathrm{hPa}$. The higher the $K$ index, the higher the probability of thunderstorms. As $K$ index increases from a value of 20 or so, the likelihood of showers and thunderstorms is expected to increase. The $K$ index was developed for forecasting air mass thunderstorms, particularly useful in predicting non-frontal thunderstorm situations.

\section{A6 KO index}

KO index was developed for estimating thunderstorm potential in Europe (Andersson et al., 1989). The KO index de- 
scribes the potential instability between lower and higher levels of the atmosphere and is thus based on the equivalent potential temperature $\theta e$ as

$\mathrm{KO}=\left(\left(\theta e_{500}+\theta e_{700}\right)-\left(\theta e_{850}+\theta e_{1000}\right)\right) / 2$.

If the surface level is above $1000 \mathrm{mb}$, then $\theta e_{\text {srf }}$ is used instead of $\theta e_{1000}$. The $\mathrm{KO}$ is more sensitive to moisture than other stability indices and is best used in cooler, moist climates. The thunderstorm potential increases as the KO index decreases. Values smaller than 2 generally indicate strong thunderstorm potential.

\section{A7 Lifted index}

The lifted index (LI), developed by Galway (1956), is nominally identical to the Showalter index, except for the determination of the level from which the parcel is lifted.

$\mathrm{LI}=T_{500}-T_{\mathrm{L}}$

The LI was defined by lifting the parcel adiabatically from the midpoint of the surface layer to $500 \mathrm{mb}$, where its temperature, considered the updraft temperature within a developing cloud, was compared to that of the environment. The parcel being lifted is defined by the dry adiabat running through the predicted surface afternoon temperature maximum and the mean mixing ratio in the lowest $900 \mathrm{~m}$. The values of this index tend to be somewhat lower than those of the Showalter index.

\section{A8 Microburst day potential index (MDPI)}

The microburst day potential index (MDPI) was developed in part on the results from the Microburst and Severe Thunderstorm (MIST) project (Atkins and Wakimoto, 1991). MDPI is based on the vertical profiles of equivalent potential temperature and is defined follows:

$$
\begin{aligned}
\mathrm{MDPI}= & (\operatorname{Max} \theta e(\operatorname{Sfc}-850 \mathrm{mb})- \\
& \operatorname{Min} \theta e(660-<500 \mathrm{mb}) / 30 \mathrm{kts} .
\end{aligned}
$$

MDPI was designed to determine likely and unlikely environments for downbursts. For MDPI values greater than or equal to 1 , microbursts are likely.

\section{A9 Showalter index}

The Showalter index (SI) was designed originally for thunderstorm forecasting in the southwestern US (Showalter, 1947). It estimates the potential instability of the 850-500 mb layer by measuring the buoyancy at $500 \mathrm{mb}$ of an air parcel lifted to that level. Thus, it is defined as

$\mathrm{SI}=T_{500}-T_{\mathrm{L}}$,

where $T_{\mathrm{L}}$ is the temperature $\left({ }^{\circ} \mathrm{C}\right)$ of a parcel lifted from 850 to $500 \mathrm{mb}$, dry-adiabatically to saturation and moistadiabatically above that. As the index decreases to 0 and below, the likelihood of showers and thunderstorms is considered to increase. SI values $\leq+3$ are indicative of possible thunderstorm activity, while values $\leq-3$ are associated with severe convective activity. The SI has been one of the most frequently applied stability indices.

\section{A10 $S$ index (STT)}

The $S$ index (STT) was introduced by the German Military Geophysical Office as an improvement on the total totals index (Haklander and Van Delden, 2003, and references therein) including a variable parameter A based on vertical totals (VT). The $S$ index is defined as

$$
\begin{aligned}
\mathrm{STT}= & \mathrm{TT}-\left(T_{700}+\mathrm{Td}_{700}\right)-A=T_{850}+\mathrm{Td}_{850} \\
& -2 \times T_{500}-\left(T_{700}-\mathrm{Td}_{700}\right)-A,
\end{aligned}
$$

where TT indicates total totals index (see below) and $A$ depends on VT such that it penalizes cases with low values of VT (i.e. low vertical temperature gradients):

$A=0$ (if VT $>25) ; 2$ (if $22<=\mathrm{VT}<=25) ; 6($ if $\mathrm{VT}<22$ ).

Note that the $S$ index takes the same variables into account as the $K$ index, but in other proportions, and thus it can also be written as

$\mathrm{STT}=\mathrm{KI}-T_{500}-A$.

\section{A11 T1 gust}

The T1 gust (also called dry stability index) method was developed with the intent of giving forecasters a way to estimate maximum thunderstorm wind gusts (Fawbush and Miller, 1954). The T1 method is still used to predict the maximum wind gust in air mass thunderstorms, relying on evidence that most convective wind gusts at the surface appear to result from downdraft air originating in the lower portion of a thunderstorm. Thus, the T1 method is computed as the difference between the temperature of a parcel of moist surface air raised moist-adiabatically to $600 \mathrm{mb}\left(T_{\mathrm{MA}} 600\right)$ and the observed dry bulb temperature at the $600 \mathrm{mb}$ level.

$\mathrm{T} 1=T_{\mathrm{MA} 600}-T_{600}$

In the case of a temperature inversion within $150-200 \mathrm{hPa}$ above the surface, the moist adiabat is followed from the warmest point in the inversion to $600 \mathrm{mb}$ (Miller, 1972). Finally, the speed of maximum wind gust (in knots) is given by the empirical formula T1 gust $=6.737+3.503 \times \mathrm{T} 1-0.0463 \times$ $\mathrm{T} 1^{2}$.

\section{A12 Thompson index}

The Thompson index (TI) is primarily used to determine thunderstorm potential in the Rocky Mountains. It is defined as

$\mathrm{TI}=\mathrm{KI}-\mathrm{LI}$. 
The Thompson index should be an improvement of KI, since KI neglects latent instability below $850 \mathrm{hPa}$. Thunderstorm potential is considered weak for values below 30 , while it becomes strong for values greater than 35 .

\section{A13 Total totals}

The total totals (TT) index is attributable to Miller (1972) and is defined by the combination of the vertical totals $\left(\mathrm{VT}=T_{850} T_{500}\right)$ and the cross totals $\left(\mathrm{CT}=\mathrm{Td}_{850}-T_{500}\right)$, resulting in

$\mathrm{TT}=T_{850}+\mathrm{Td}_{850}-2 \times T_{500}$.

The TT index is commonly used as a severe weather indicator. The higher the number, the more unstable the atmosphere. Values lower than $45^{\circ} \mathrm{C}$ generally indicate weak thunderstorm potential, while values larger than $55^{\circ} \mathrm{C}$ indicate high possibility of severe thunderstorms, though value interpretation varies with season and location.

\section{A14 TQ index}

The TQ index (TQ) is used to assess the potential for lowtopped convection. It is defined as

$\mathrm{TQ}=\left(T_{850}+\mathrm{Td}_{850}\right)-1.7 \times\left(T_{700}\right)$.

Values larger than 12 indicate unstable lower troposphere, where thunderstorm and rainfall are possible outside of stratiform clouds; while for values larger than 17, thunderstorm and rainfall are possible in the presence of stratiform clouds. 
Acknowledgements. Part of this work was stimulated through the EU COST Actions ES0702 EG-CLIMET and ES1303 TOPROF. Environment Canada and the German Weather Service (Deutscher Wetterdienst) conducted microwave profiler and radiosonde data collection in Whistler and Lindenberg, respectively, and provided grant support for data analysis.

Edited by: U. Wandinger

\section{References}

American Meteorological Society Glossary of Meteorology (AMS): available at: http://glossary.ametsoc.org/wiki/Main_Page, last access: 6 November 2013.

Andersson, T., Andersson, M., Jacobsson, C., and Nilsson, S.: Thermodynamic indices for forecasting thunderstorms in southern Sweden, Meteorol. Mag., 116, 141-146, 1989.

Atkins, N. T. and Wakimoto, R. M.: Wet microburst activity over the southeastern United States: Implications for Forecasting, Weather Forecast., 6, 470-482, 1991.

Cadeddu, M. P., Liljegren, J. C., and Turner, D. D.: The Atmospheric radiation measurement (ARM) program network of microwave radiometers: instrumentation, data, and retrievals, Atmos. Meas. Tech., 6, 2359-2372, doi:10.5194/amt-6-2359-2013, 2013.

Chan, P. W.: Performance and application of a multiwavelength, ground-based microwave radiometer in intense convective weather, Meteorol. Z., 18, 253-265, 2009.

Chan, P. W. and Hon, K. K.: Application of ground-based, multichannel microwave radiometer in the nowcasting of intense convective weather through instability indices of the atmosphere, Meteorol. Z., 20, 431-440, 2011.

Chan, P. W. and Lee, Y. F.: Application of a ground-based, multichannel microwave radiometer to the alerting of low-level windshear at an airport, Meteorol. Z., 20, 423-429, 2011.

Cimini, D., Westwater, E. R., Han, Y., and Keihm, S. J.: Accuracy of Ground-based Microwave Radiometer and Balloon-Borne Measurements During WVIOP2000 Field Experiment, IEEE Trans. Geosci. Remote Sens., 41, 2605-2615, 2003.

Cimini, D., Hewison, T. J., Martin, L., Güldner, J., Gaffard, C., and Marzano, F.: Temperature and humidity profile retrievals from groundbased microwave radiometers during TUC, Meteorol. Z., 15, 45-56, 2006.

Cimini, D., Westwater, E. R., and Gasiewski, A. J.: Temperature and humidity profiling in the Arctic using millimeter-wave radiometry and 1-DVAR, IEEE Trans. Geosci. Remote Sens., 48, 1381-1388, doi:10.1109/TGRS.2009.2030500, 2010.

Cimini, D., Campos, E., Ware, R., Albers, S., Giuliani, G., Oreamuno, J., Joe, P., Koch, S., Cober, S., and Westwater, E.: Thermodynamic Atmospheric Profiling during the 2010 Winter Olympics Using Ground-based Microwave Radiometry, IEEE Trans. Geosci. Remote Sens., 49, 4959-4969, doi:10.1109/TGRS.2011.2154337, 2011.

Cimini, D., Caumont, O., Löhnert, U., Alados-Arboledas, L., Bleisch, R., Huet, T., Ferrario, M. E., Madonna, F., Haefele, A., Nasir, F., Pace, G., and Posada, R.: A data assimilation experiment of temperature and humidity profiles from an international network of ground-based microwave radiometers, Proc. Microrad 2014, Pasadena, USA, 24-27 March 2014.

de Coning, E., Koenig, M., and Olivier, J.: The combined instability index: a new very-short range convection forecasting technique for southern Africa, Meteorol. Appl., 18, 421-439, doi:10.1002/met.234, 2011.

Doswell III, C. A. and Schultz, D. M.: On the Use of Indices and Parameters in Forecasting Severe Storms, Electronic Journal of Severe Storms Meteorology, 1, 1-22, available at: http://www. ejssm.org/ojs/index.php/ejssm/article/view/11/10, 2006.

Fawbush, E. J. and Miller, R. C.: A Basis for Forecasting Peak Wind Gusts in Non-Frontal Thunderstorms, Bull. Am. Meteorol. Soc., 35, 14-19, 1954.

Feltz, W. F. and Mecikalski, J. R.: Monitoring High-TemporalResolution Convective Stability Indices Using the Ground-Based Atmospheric Emitted Radiance Interferometer (AERI) during the 3 May 1999 Oklahoma-Kansas Tornado Outbreak, Weather Forecast., 17, 445-455, 2002.

Friedrich, K., Lundquist, J. K., Aitken, M., Kalina, E. A., and Marshall, R. F.: Stability and turbulence in the atmospheric boundary layer: A comparison of remote sensing and tower observations, Geophys. Res. Lett., 39, L03801, doi:10.1029/2011GL050413, 2012.

Galway, J. G.: The lifted index as a predictor of latent instability, Bull. Am. Meteorol. Soc., 37, 528-529, 1956.

George, J. J.: Weather Forecasting for Aeronautics. Academic Press, New York, 673 pp., 1960.

Güldner, J. and Spänkuch, D.: Remote sensing of the thermodynamic state of the atmospheric boundary layer by ground-based microwave radiometry, J. Atmos. Oceanic Technol., 18, 925933, 2001.

Haklander, A. J. and Van Delden, A.: Thunderstorm predictors and their forecast skill for the Netherlands, Atmos. Res., 67-68, 273299, doi:10.1016/S0169-8095(03)00056-5, 2003.

Hart, R. E. and Forbes, G. S.: The Use of Hourly Model-Generated Soundings to Forecast Mesoscale Phenomena, Part II: Initial Assessment in Forecasting Nonconvective Strong Wind Gusts, Weather Forecast., 14, 461-469, 1999.

Hart, R. E., Forbes, G. S., and Grumm, R. H.: The Use of Hourly Model-Generated Soundings to Forecast Mesoscale Phenomena. Part I: Initial assessment in forecasting warm-season phenomena, Weather Forecast., 13, 1165-1185, 1998.

Hewison, T.: 1D-VAR retrievals of temperature and humidity profiles from a ground-based microwave radiometer, IEEE Trans. Geosci. Remote Sens., 45, 2163-2168, 2007.

Holtslag, M. C., Steeneveld, G. J., and Holtslag, A. A. M.: Fog forecasting: "old fashioned" semi-empirical methods from radio sounding observations versus "modern" numerical models, Proc. 5th Int. Conf. Fog and Dew (FOGDEW2010), available at: http://meetingorganizer.copernicus.org/FOGDEW2010/ FOGDEW2010-69.pdf (last access: 8 November 2013), Münster, Germany, 25-30 July 2010.

Knupp, K., Ware, R., Cimini, D., Vandenberghe, F., Vivekanandan, J., Westwater, E. R., and Coleman, T.: Groundbased passive microwave profiling during dynamic weather conditions, J. Atmos. Ocean. Technol., 26, 1057-1073, doi:10.1175/2008JTECHA1150.1, 2009. 
König, M.: Atmospheric Instability Parameters Derived from MSG SEVIRI Observations, EUMETSAT Technical Memorandum No. 9, January 2002.

Koenig, M. and de Coning, E.: The MSG Global Instability Indices product and its use as a nowcasting tool, Weather Forecast., 24, 272-285, 2009.

Kuhlman, C. J.: Evaluation of Convective Wind Forecasting Methods During High Wind Events, Master's Thesis, Naval Postgraduate School, Monterey, California, March 2006.

Löhnert, U. and Maier, O.: Operational profiling of temperature using ground-based microwave radiometry at Payerne: prospects and challenges, Atmos. Meas. Tech., 5, 1121-1134, doi:10.5194/amt-5-1121-2012, 2012.

Löhnert, U., Crewell, S., and Simmer, C.: An integrated approach towards retrieving physically consistent profiles of temperature, humidity, and cloud liquid water, J. Appl. Meteorol., 43, 12951307, 2004.

Madhulatha, A., Rajeevan, M., Venkat Ratnam, M., Bhate, J., and Naidu, C. V.: Nowcasting severe convective activity over southeast India using ground-based microwave radiometer observations, J. Geophys. Res. Atmos., 118, 1-13, doi:10.1029/2012JD018174, 2013.

Mailhot, J., Belair, S., Charron, M., Doyle, C., Joe, P., Abrahamowicz, M., Bernier, N. B., Denis, B., Erfani, A., Frenette, R., Giguere, A., Isaac, G. A., McLennan, N., McTaggart-Cowan, R., Milbrandt, J., and Tong, L.: Environment Canada's experimental numerical weather prediction systems for the Vancouver 2010 Winter Olympic and Paralympic games, Bull. Amer. Meteorol. Soc., 11, 1073-1085, 2010.

Maschwitz, G., Löhnert, U., Crewell, S., Rose, T., and Turner, D. D.: Investigation of ground-based microwave radiometer calibration techniques at $530 \mathrm{hPa}$, Atmos. Meas. Tech., 6, 2641-2658, doi:10.5194/amt-6-2641-2013, 2013.

Miller, R. C.: Notes on analysis and severe storm forecasting procedures of the Air Force Global Weather Central. Technical Report 200(R), AWS, USAF, Scott AFB, IL, 1972.

National Research Council Committee on Developing Mesoscale Meteorological Observational Capabilities to Meet Multiple Needs (NRC): Observing Weather and Climate from the Ground Up: A Nationwide Network of Networks, ISBN: 978-0-30912986-2, 250 pp., 2008.
National Research Council Committee on Progress and Priorities of U.S. Weather (NRC): Research and Research-to-Operations Activities, When Weather Matters: Science and Service to Meet Critical Societal Needs, ISBN: 978-0-309-15249-5, 198 pp., 2010.

Peppier, R. A.: A Review of Static Stability Indices and Related Thermodynamic Parameters, Illinois State Water Survey Division, SWS Miscellaneous Publication 104, available at: http: //www.isws.illinois.edu/pubdoc/MP/ISWSMP-104.pdf (last access: 7 November 2013), October, 1988.

Showalter, A. K.: A stability index for forecasting thunderstorms, Bull. Am. Meteorol. Soc., 34, 250-252, 1947.

Solheim, F., Godwin, J., Westwater, E., Han, Y., Keihm, S., Marsh, K., and Ware, R.: Radiometric profiling of temperature, water vapor, and cloud liquid water using various inversion methods, Rad. Sci., 33, 393-404, 1998.

Vaisala: Radiosonde RS92-SGP, Ref. B210358ENF Vaisala 2013, available at: http://www.vaisala. com/VaisalaDocuments/BrochuresandDatasheets/

RS92SGP-Datasheet-B210358EN-F-LOW.pdf, last access: 6 November 2013.

Venkat Ratnam, M., Durga Santhi, Y., Rajeevan, M., and Vijaya Bhaskara Rao, S.: Diurnal variability of stability indices observed using radiosonde observations over a tropical station: Comparison with microwave radiometer measurements, Atmos Res., 124, 21-33, doi:10.1016/j.atmosres.2012.12.007, 2013.

Wagner, T. J., Feltz, W. F., and Ackerman, S. A.: The temporal evolution of convective indices in storm-producing environments, Weather Forecast., 23, 786-794, 2008.

Ware, R., Solheim, F., Carpenter, R., Güldner, J., Liljegren, J., Nehrkorn, T., and Vandenberghe, F.: A multi-channel radiometric profiler of temperature, humidity and cloud liquid, Rad. Sci., 38, 1-13, 2003.

Ware, R., Cimini, D., Campos, E., Giuliani, G., Albers, S., Nelson, M., Koch, S. E., Joe, P., and Cober, S.: Thermodynamic and Liquid Profiling during the 2010 Winter Olympics, Atmos. Res., 132-133, 278-290, doi:10.1016/j.atmosres.2013.05.019, 2013.

Xu, G., Ware, R., Zhang, W., Feng, G., Liao, K., and Liu, Y.: Effect of off-zenith observation on reducing the impact of precipitation on ground-based microwave radiometer measurement accuracy in Wuhan, Atmos. Res., 140-141, 85-94, 2014. 